Estudios Constitucionales, Año 16, No 2, 2018, pp. 183-220

ISSN 07180195

Centro de Estudios Constitucionales de Chile Universidad de Talca

"El control parlamentario del gobierno en funciones en España: la experiencia de la XI legislatura (2016)" David Delgado Ramos

\title{
EL CONTROL PARLAMENTARIO DEL GOBIERNO EN FUNCIONES EN ESPAÑA: LA EXPERIENCIA DE LA XI LEGISLATURA (2016)*
}

\author{
PARLIAMENTARY CONTROL OF THE CARETAKER GOVERNMENT IN SPAIN: \\ THE EXPERIENCE OF THE $11^{\mathrm{TH}}$ TERM (2016)
}

\author{
David Delgado Ramos* \\ Universidad Nacional de Educación a Distancia (Madrid, España) \\ davdelgado@madrid.uned.es.
}

RESUMEN: La interinidad gubernamental surgida tras las elecciones generales del 20 de diciembre de 2015 en España, que debia ser breve en espera de la investidura y formación del nuevo Gobierno, trajo consigo una situación inédita en la historia político-constitucional española: la permanencia en funciones del Gobierno cesado durante casi un año.

Su excesiva duración, y el hecho de que tanto el poder legislativo se encontrase en funcionamiento mientras que el poder ejecutivo estaba limitado, suscitó la controversia acerca del ejercicio de la función parlamentaria de control a un gobierno en situación de interinidad, limitado política y jurídicamente.

Controversia aún no resuelta y que alcanzó su punto álgido con la interposición ante el Tribunal Constitucional de un conflicto entre órganos constitucionales entre Poderes del Estado, el tercero de nuestra historia constitucional y el primero interpuesto por el Parlamento.

A lo largo de este trabajo pretendemos analizar la controversia suscitada, la naturaleza del Gobierno en funciones y la función de control, además de un estudio de derecho comparado.

ABSTRACT: The interim Government that emerged after the December 20th, 2015 general election in Spain, which was to be brief in pending the investiture and formation of the new Government, brought with it an unprecedented situation in the Spanish politic and constitutional history: the permanency of a ceased Government for almost a year.

\footnotetext{
* Trabajo recibido el 23 de octubre de 2017 y aprobado el 6 de junio de 2018.

Una versión mucho más amplia de este trabajo ha sido recientemente publicada por la Editorial Aranzadi dentro de la obra Problemas actuales del derecho parlamentario.

** Profesor-Tutor de Derecho Constitucional, Universidad Nacional de Educación a Distancia (Madrid, España), Licenciado en Derecho y Licenciado en Ciencias Políticas y de la Administración por la Universidad Pontificia Comillas de Madrid-Icade (España), Doctor en Derecho por la Università degli studi di Verona (Italia), Máster en Derecho Parlamentario, Elecciones y Estudios Legislativos por la Universidad Complutense de Madrid (España).
} 
Its excessive length, and the fact that both the legislative branch is located in running while the Executive power was limited, gave rise to the controversy about the exercise of parliamentary control function to a Government in situation of interim, limited political and legally.

Still an unresolved controversy and which reached its peak with the filing before the Constitutional Court of a conflict of powers between two of the State's branches, the third in our constitutional history and the first one being filed by the Parliament.

Throughout this work, we intend to analyze raised controversy, the nature of the acting Government's nature and the Parliaments function of controlling the Government's performance, as well as a study of comparative law.

PALABRAS CLAVE: Gobierno cesante, control parlamentario, conflicto, poder.

KEY WORDS: Caretaker government, parliamentary control, conflict, power.

\section{INTRODUCCIÓN}

La XI Legislatura en las Cortes Generales, la más breve de la historia democrática $^{1}$, ha conllevado la aparición de una experiencia insólita en las relaciones Gobierno-Parlamento, que ni el Constituyente ni el Derecho Parlamentario previeron o pudieron prever: un enconado debate en torno al posible control parlamentario del Gobierno en funciones.

La dilación en la formación del Gobierno, en funciones desde el 21 de diciembre de $2015^{2}$, supuso que, tras la constitución de las Cámaras el 13 de enero de 2016, el inicio de la actividad del legislativo no fuese parejo al del ejecutivo.

Esta situación conllevó que ambos poderes se encontrasen, por vez primera, desacompasados, con un poder, -el Legislativo-, en plenitud de funciones y otro, -el Ejecutivo- con sus funciones limitadas, en situación de prorrogatio. Un escenario que se agravó con el paso de los meses, en los que se mantenía la parálisis gubernamental mientras que el Parlamento se encontraba activo y pleno de actividad.

Para el Gobierno, su permanencia en funciones, de honda limitación jurídica y fáctica, le colocaba en una posición incómoda, toda vez que consideraba que, dado que carecía de la confianza parlamentaria del Congreso, que provenía de un Congreso extinto al haber caducado la X Legislatura, no debía someterse al control parlamentario de una Cámara que no le había otorgado su confianza.

1111 días en total, del 13 de enero al 3 de mayo de 2016. Curiosamente, la legislatura precedente, la X Legislatura (13 diciembre de 2011-12 de enero de 2016), ha sido, en cambio, la de mayor duración.

2 El Gobierno español se mantuvo en prorrogatio desde el 21 de diciembre de 2015 hasta el 31 de octubre de 2016, 316 días en total. 
En suma, sin relación fiduciaria entre el Parlamento y el Gobierno no cabía la posibilidad de ejercer el control parlamentario.

Para el Congreso de los Diputados, actor principal en lo relativo a la función de control parlamentario y a la función legislativa, el planteamiento era diferente, al considerar que, aunque el ejecutivo se encontrase en funciones a la espera de la conformación de uno nuevo, existía Gobierno y que, por lo tanto, debía someterse a su control, dado que la situación de interinidad gubernamental no suspendía el ejercicio de la función de control. Si hay Gobierno, en definitiva, debía haber control parlamentario al mismo.

Como consecuencia de esta confrontación entre el Ejecutivo y el Congreso, se planteó a principios de junio, una vez disueltas las Cámaras, un conflicto entre órganos constitucionales ante el Tribunal Constitucional, al objeto de dilucidar si, en un contexto de Gobierno en funciones, el Parlamento encuentra limitada su potestad de control parlamentario.

El objetivo de este trabajo consiste en estudiar esa cuestión, analizando el rol del Gobierno en funciones y la praxis del control parlamentario durante la brevísima XI Legislatura, al objeto de responder a la pregunta sobre si ha existido control al ejecutivo por parte del Parlamento y, de ser afirmativa la respuesta, examinar su alcance y consecuencias.

\section{EL GOBIERNO EN FUNCIONES}

El Gobierno en funciones ${ }^{3}$, -que no en período electoral- ${ }^{4}$, como órgano colegiado que se encuentra cesado ${ }^{5}$, está sometido a una fuerte limitación en

3 La explicación de este concepto, cuya denominación más propia debiera ser la de "cesante", tal y como lo define la Constitución, es aclarado por el diccionario de la Real Academia de la Lengua a partir de la distinción entre los conceptos de "en función" y "en funciones", siendo el primero entendido como "en ejercicio de su cargo", mientras que el segundo como "en sustitución de quien ejerce en propiedad el cargo". Además, existe la situación administrativa de "en prolongación de funciones", que se produce cuando se suprimen o modifican determinados órganos administrativos cuyo titular ostenta la consideración de alto cargo. En este caso, y dado que los altos cargos son nombrados y cesados por un real decreto distinto del de creación del órgano del que son titulares, la supresión o modificación de ese órgano no conlleva el cese de su titular, que se mantiene en sus funciones hasta que se produzca su cese expreso por real decreto.

4 Convocadas las elecciones generales, se inicia el período electoral. El período electoral, tal y como se establece en el artículo 1.2 de la Instrucción 2/2011, de 24 de marzo, de la Junta Electoral Central, sobre interpretación del artículo 50 de la Ley Orgánica del Régimen Electoral General, en relación con el objeto y los límites de las campañas institucionales y de los actos de inauguración realizados por los poderes públicos en período electoral, es el comprendido entre la publicación del real decreto de convocatoria de las elecciones y el día en el que se produce la votación. El Gobierno en período electoral goza todas las 
su actuación, derivada de las restricciones propias del marco jurídico que define su situación, debiendo estar presidido el desempeño de sus funciones, en todo caso, por la "máxima contención" 6 .

Así, la Constitución, en su artículo 101.27, el único artículo dedicado a esta cuestión, expone que "El Gobierno cesante continuará en funciones hasta la toma de posesión del nuevo Gobierno".

Posteriormente, la Ley No 50/1997, de 27 de noviembre, del Gobierno, en desarrollo del precepto constitucional, recogió la primera regulación sobre el Gobierno en funciones, explicando en su exposición de motivos que "con base en el principio de lealtad constitucional, delimitando su propia posición constitucional y entendiendo que el objetivo último de toda su actuación radica en la consecución de un normal desarrollo del proceso de formación del nuevo Gobierno".

Así lo expuso en el artículo 21 de la Ley ${ }^{8}$, que pretendía delimitar el contenido de las competencias propias de un Gobierno en situación temporal de interini-

facultades, aunque limitado, según el artículo 50.2 y 3 de la LOREG, en lo relativo a la prohibición de campañas institucionales, de logros y de inauguraciones, para evitar, como señala la misma instrucción, que se "atente contra los principios de objetividad y transparencia del proceso electoral y de igualdad entre los actores electorales", con dos excepciones: campañas institucionales sobre el ejercicio del derecho al sufragio y campañas informativas que resulten imprescindibles para la salvaguarda del interés público o para el correcto desenvolvimiento de los servicios públicos.

5 Desde un punto de vista formal, el Gobierno, a tenor de lo dispuesto en el artículo 101.1 de la Constitución "cesa tras la celebración de las elecciones generales", de tal suerte que, el día después de las elecciones se tramitan dos reales decretos, que se publicarán al día siguiente, por el que en el primero se declara el cese del Presidente del Gobierno y, en el segundo, el de los miembros del Gobierno. Ambos, refrendados por el Presidente del Gobierno, establecen expresamente que "continuarán en funciones hasta la toma de posesión del nuevo Gobierno".

6 De la Peña (1998), p. 347.

7 Artículo 101 CE:

"1. El Gobierno cesa tras la celebración de elecciones generales, en los casos de pérdida de la confianza parlamentaria previstos en la Constitución, o por dimisión o fallecimiento de su Presidente.

2. El Gobierno cesante continuará en funciones hasta la toma de posesión del nuevo Gobierno".

8 Artículo 21 de la Ley $N^{\circ}$ 50/97, de 27 de noviembre:

"1. El Gobierno cesa tras la celebración de elecciones generales, en los casos de pérdida de confianza parlamentaria previstos en la Constitución, o por dimisión of fallecimiento de su Presidente.

2. El Gobierno cesante continúa en funciones hasta la toma de posesión del nuevo Gobierno, con las limitaciones establecidas en esta Ley.

3. El Gobierno en funciones facilitará el normal desarrollo del proceso de formación del nuevo Gobierno y el traspaso de poderes al mismo y limitará su gestión al despacho ordinario de los asuntos públicos, absteniéndose de adoptar, salvo casos de urgencia debidamente acreditados o por razones de interés general cuya acreditación expresa asi lo justifique, cualesquiera otras medidas.

4. El Presidente del Gobierno en funciones no podrá ejercer las siguientes facultades: 
dad, por encontrarse cesado, articulándolo en torno a un marco definido por dos conceptos: facilitar el traspaso de poderes al nuevo Gobierno y el despacho ordinario de los asuntos públicos 9 .

Respecto del traspaso de poderes, este se ejerce, en casos de mayoría parlamentaria clara, a partir del día siguiente al de las elecciones, tomando conocimiento el equipo del partido político vencedor encargado del traspaso de los diversos asuntos en trámite en los distintos Departamentos ministeriales, así como de las reuniones de los órganos colegiados gubernamentales, como la Comisión General de Secretarios de Estado y Subsecretarios y de la Comisión Delegada del Gobierno para Asuntos Económicos, entre otras.

En lo relativo al despacho ordinario de los asuntos, y teniendo en cuenta que la situación de Gobierno en funciones no impide la celebración de Consejos de Ministros donde se aprueba normativa ${ }^{10}$, la cuestión, más etérea en cuanto a su definición por ser un concepto jurídico indeterminado, requiere de un proceso de exégesis, toda vez que su alcance no se encuentra precisado con claridad, lo que reclama un análisis de cada caso concreto que, en cualquier caso, debe estar precedido por el principio de prudencia, para no condicionar la actuación del Gobierno entrante.

Hay que tener en cuenta que, dentro del concepto de despacho ordinario de los asuntos públicos, se encuentran no sólo actos estrictamente administrativos cuya

a) Proponer al Rey la disolución de alguna de las Cámaras, o de las Cortes Generales.

b) Plantear la cuestión de confianza.

c) Proponer al Rey la convocatoria de un referéndum consultivo.

5. El Gobierno en funciones no podrá ejercer las siguientes facultades:

a) Aprobar el Proyecto de Ley de Presupuestos Generales del Estado.

b) Presentar proyectos de ley al Congreso de los Diputados o, en su caso, al Senado.

6. Las delegaciones legislativas otorgadas por las Cortes Generales quedarán en suspenso durante todo el tiempo que el Gobierno esté en funciones como consecuencia de la celebración de elecciones generales".

9 Este criterio general cuenta con dos excepciones, comprensibles, contenidas en el artículo 21.3 de la Ley del Gobierno, y circunscritas a "casos de urgencia debidamente acreditados" o "razones de interés general cuya acreditación expresa asi lo justifique". Cuestiones que, sin perjuicio del eventual control político que se efectúe por la Diputación Permanente, -en caso de no estar constituida la Cámara-, podrán ser fiscalizadas por la jurisdicción contencioso-administrativa.

10 Son pocos Consejos de Ministros, -siete tras las elecciones generales de 1996, cinco tras las de 2000, otros cinco tras las de 2004, tres tras las de 2008 y cinco tras las de 2011-, pero en los que se siguen aprobando abundantes reales decretos, -nada menos que 277 reales decretos en 1996, 160 en el año 2000, 83 en 2004, 38 en el año 2008 y 69 en 2011-, y Acuerdos del Consejo de Ministros, -657 en el año 1996, 216 en 2000, 193 en el año 2004, 25 en 2008 y 195 en 2011-. Además, se han llegado a aprobar tres reales decretos leyes en 1993 y uno en 2011. 
naturaleza se encuentra plenamente definida y determinada por la ley y, por lo tanto, sin margen de apreciación discrecional posible sino que, también, los hay con un margen aún más difuso en los que, si no interviene en su conclusión el pleno e ilimitado ejercicio de la función de indirizzo político ${ }^{11}$ del Gobierno, nada obstaría, en principio, para considerarlos ordinarios o de mero trámite.

Quizá por ello, este concepto ha sido objeto de interpretación a partir del año 2005 por parte del Tribunal Supremo en diversas sentencias que muestran una evolución jurisprudencial en la materia, aunque todas ellas han pretendido delimitar y clarificar el marco jurídico de indeterminación del concepto.

La primera de ellas, la sentencia 5639/2005, de 20 de septiembre, -estimativa $^{12}$ de un recurso contra un Acuerdo del Consejo de Ministros que, encontrándose en funciones, resolvió conceder una extradición-, afirmó que, por despacho ordinario de asuntos, debía entenderse "la gestión administrativa ordinaria ausente de valoraciones y decisiones en las que entren criterios politicos".

En ese sentido, se basa para estimar el recurso en el artículo 6.2 de la Ley 4/1985, de 21 de marzo, de extradición pasiva, según la cual, cuando la extradición ha sido declarada judicialmente procedente, "no será vinculante para el Gobierno que podrá denegarla en el ejercicio de la soberanía nacional, atendiendo al principio de reciprocidad o a razones de seguridad, orden público o demás intereses esenciales de España".

Se aprecia así que, en ese caso, el Gobierno debe formular un juicio valorativo para estimar si concurren estas circunstancias y que, precisamente por ello, al haberla realizado un Gobierno en funciones "ejercita siempre una facultad de valoración de los intereses nacionales que conlleva un juicio político que excede de la gestión ordinaria de los asuntos públicos, y priva al futuro Gobierno de una decisión politica que en el ejercicio de la soberanía nacional le corresponde en orden a conceder o denegar la extradición pasiva".

Por otro lado, considera que cuando el artículo 21.3 de la Ley del Gobierno declara que el Gobierno en funciones "limitará su gestión al despacho ordinario de

11 Para Brage y Reviriego, una cosa es "que el Gobierno, por hallarse en esta situación, pueda verse restringido en su labor de 'dirección politica' al 'despacho ordinario', pero sin que, en nuestro criterio, este último concepto excluya la 'dirección política' en sí misma, pues un Gobierno, en funciones o no, sin 'dirección política' no sería ya un Gobierno, simplemente". BRAGE y ReVIRIEgo (2006), p. 453.

12 Como recuerda Reviriego, "Estamos ante la única ocasión hasta la fecha en que una decisión de un Gobierno en funciones ha sido anulada por los tribunales por considerarse extramuros de su ámbito de actuación, bien ordinario, bien extraordinario (urgencia o interés general)". REVIRIEGO (2017), p. 386. 
los asuntos, absteniéndose de adoptar, salvo casos de urgencia debidamente acreditados o por razones de interés general cuya acreditación expresa asi lo justifique, cualesquiera otras medidas" se está refiriendo a una "gestión administrativa ordinaria ausente de valoraciones y decisiones en las que entren criterios políticos salvo que se motive debidamente la urgencia o las razones de interés general que justifiquen la adopción de medidas de otra naturaleza".

En definitiva, como no mediaba urgencia ni se apreciaban razones de interés general en el acuerdo impugnado, el Tribunal Supremo concluyó que el Gobierno se había extralimitado al resolver sobre la extradición pasiva objeto del recurso ${ }^{13}$.

Sin embargo, apenas tres meses después, en su sentencia 8303/2005, de 2 de diciembre, -en la que se recurre la denegación de la concesión de un indulto por parte de un Gobierno en funciones-, el Tribunal clarificó aún más la indeterminación jurídica en torno al concepto de "gestión ordinaria de asuntos públicos", resaltando que lo verdaderamente relevante para analizar la posible extralimitación gubernamental no es tanto la existencia de un juicio u orientación política, sino la toma de decisiones que, en un contexto y circunstancia concretas, conlleven un cambio en la orientación política o puedan llegar a condicionar, comprometer o impedir las que el nuevo Gobierno deba adoptar.

Fruto de esta clarificación conceptual, el Tribunal resaltó cuatro aspectos: que el Gobierno es Gobierno hasta la constitución del nuevo Gabinete, que su actuación debe ser restrictiva, que su situación de interinidad no excluye per se el control parlamentario y que el estado de cesante y en funciones, y de potestades limitadas conlleva, en el control judicial, un análisis caso a caso para observar si se han excedido los contornos de su acotada capacidad de acción.

Así, para el Tribunal, que "el Gobierno cesante debe seguir gobernando hasta que sea sustituido efectivamente por el nuevo. La Constitución es tajante, ordena al Gobierno que continúe ejerciendo sus funciones tras su cese y no excluye expresamente ninguna de entre las que quiere que sigan siendo ejercidas. Se comprende

13 Brage y Reviriego entienden que el Tribunal fue excesivamente restrictivo, interpretando lo dispuesto en la Ley del Gobierno de un modo literal y que, precisamente por ello, "es aceptable considerar que los Acuerdos del Gobierno sobre extradición son 'actos de soberanía', pero ello es algo compatible con la 'gestión ordinaria' de los asuntos como actividad normal de un Gobierno en funciones, pues esa 'gestión ordinaria'-dejando ahora de lado los casos de urgencia o en que esté en juego el interés general- no excluye el ejercicio de soberanía nacional; dicho de otro modo, el ejercicio de la soberanía nacional no convierte, en sí mismo, a una actuación del Gobierno en funciones en una 'gestión extraordinaria". BRAGE y ReVIRIEGO (2006), p. 469. 
sin dificultad que España no puede quedarse sin Gobierno ni siquiera unas horas. También que el hecho de que no se establezcan limites explicitos a la actuación del Gobierno en funciones no quiere decir que no existan pues la propia naturaleza de esta figura, cesante y transitoria, conlleva su falta de aptitud para ejercer la plenitud de las atribuciones gubernamentales" (FJ 5).

Además, al referirse a las relaciones entre el Gobierno cesante y el Parlamento, especifica que "Resulta, igualmente, de la distinta naturaleza de las causas de cese del Gobierno que su condición de 'en funciones' no tiene que ir acompañada, necesariamente, de la inexistencia de control parlamentario, ni de un cambio de mayoría política en el Congreso de los Diputados. En cuanto, a lo primero, y con independencia de que las Diputaciones Permanentes de las cámaras velan por sus poderes también cuando han sido disueltas y hasta que se constituyan las surgidas de las elecciones (artículo 78 de la Constitución), es lo cierto que si el cese del Gobierno se ha producido por causa diferente de la celebración de las elecciones generales, permanecen en el goce de sus atribuciones constitucionales el Congreso de los Diputados y el Senado. Por lo que hace a lo segundo, del sufragio de los españoles puede surgir una nueva mayoría, distinta de la que sostenía al Gobierno cesante, como ocurrió en el caso que tenemos ante nosotros, pero también puede verse confirmada la anterior" (FJ 7).

Es decir, para el Tribunal Supremo, se establece una clara separación entre las causas que dan lugar a la situación de Gobierno en prorrogatio a efectos de control parlamentario, y que en el caso de cese tras un proceso electoral el control parlamentario "puede" no existir. Y esa condicionalidad, sin decirlo explícitamente, la conecta con lo expuesto en el fundamento jurídico anterior, cuando explica que, en relación con las diversas situaciones que producen un Gobierno en funciones, "la interinidad que producen puede extenderse a lo largo de varias semanas e, incluso, de varios meses si procediera la disolución de las Cortes Generales prevista en el artículo 99.5 de la Constitución ${ }^{14}$. Esta posibilidad no se ha dado hasta ahora, pero la experiencia autonómica, a partir de normas, en general, muy parecidas a las del artículo 99, ofrece ejemplos en los que se ha prolongado considerablemente un Consejo Ejecutivo en funciones ${ }^{15}$. En consecuencia, el Gobierno

\footnotetext{
14 Artículo 99.5 CE:

"Si transcurrido el plazo de dos meses, a partir de la primera votación de investidura, ningún candidato hubiere obtenido la confianza del Congreso, el Rey disolverá ambas Cámaras y convocará nuevas elecciones con el refrendo del Presidente del Congreso".

15 El Tribunal se refiere a los casos paradigmáticos de las comunidades autónomas de Cantabria y Madrid. En Cantabria, tras ser condenado por el Tribunal Superior de Justicia a pena de prisión e inhabilitación, el
} 
puede permanecer en funciones un periodo de tiempo significativo" (FJ 6). En suma, el Tribunal Supremo parece entender que, fruto de la experiencia del proceso de investidura parlamentaria, el control parlamentario carece de sentido en el caso de Gobierno cesante dada su limitada interinidad temporal pero, de igual modo, si la interinidad se ampliase, el control parlamentario debe existir. De ahí la afirmación de "necesariamente" que expone en la sentencia.

Por último, en relación con los límites de su actuación, el Supremo entiende que "el Gobierno en funciones ha de continuar ejerciendo sus tareas sin introducir nuevas directrices políticas ni, desde luego, condicionar, comprometer o impedir las que deba trazar el que lo sustituya. El cese priva a este Gobierno de la capacidad de dirección de la politica interior y exterior a través de cualquiera de los actos válidos a ese fin, de manera que será preciso examinar, caso por caso, cuando surja controversia al respecto, si el discutido tiene o no esa idoneidad en función de la decisión de que se trate, de sus consecuencias y de las circunstancias en que se deba tomar" (FJ 8).

En definitiva, el Tribunal Supremo evidencia que el concepto jurídico indeterminado del "despacho ordinario de asuntos públicos" que la ley atribuye al Gobierno cesante o en funciones "comprende todos aquellos cuya resolución no implique el establecimiento de nuevas orientaciones politicas ni signifique condicionamiento, compromiso o impedimento para las que deba fijar el nuevo Gobierno. $Y$ esa cualidad que excluye a un asunto del despacho ordinario ha de apreciarse, caso

Presidente de la Comunidad Juan Hormaechea (junio de 1987-diciembre de 1990, julio de 1991-julio de 1995) presentó su dimisión, cesando el gobierno autonómico, iniciándose inmediatamente el proceso de investidura del nuevo Presidente, que debía ser ágil no sólo por la lógica necesidad de un gobierno, sino también porque en mayo de 1995 se celebraban elecciones autonómicas en la Comunidad. Sin embargo, tras dos intentos fracasados, la imposibilidad de investir un candidato en el Parlamento dilató la interinidad del gobierno cesante, que se mantuvo en funciones desde noviembre de 1994 hasta julio de 1995, cuando tras las elecciones celebradas en mayo de 1995 resultó investido un candidato con respaldo mayoritario. Para un estudio de la cuestión y de la normativa cántabra Cfr. Reviriego (2004), pp. 373-376.

El caso de la Comunidad de Madrid, de menor duración, revistió una mayor complejidad jurídica y política. En mayo de 2003, tras la celebración de las elecciones autonómicas y locales, se conformó una nueva mayoría en la Asamblea de Madrid, manteniéndose la del Ayuntamiento, cuyo candidato a Alcalde era el entonces Presidente de la Comunidad Autónoma. El candidato a Presidente de la Comunidad que tenía mayores opciones de resultar investido no logró la investidura por la ausencia deliberada de dos diputados de su partido, lo que propició que el Presidente de la Comunidad Autónoma mantuviese "en funciones" el cargo mientras asumía el cargo de Alcalde de Madrid. Pese a que jurídicamente existían dudas acerca de la compatibilidad de ambos cargos, toda vez que la previsión normativa autonómica establecía la incompatibilidad, retuvo ambos cargos en calidad de "Alcalde-Presidente" desde el 23 de junio hasta el 21 de noviembre de 2003, cuando se celebraron nuevamente elecciones autonómicas en la Comunidad de Madrid, que produjeron un vuelco electoral con una clara mayoría absoluta en la Asamblea, resultando investido otro candidato. De nuevo, para un análisis en profundidad Cfr. Reviriego (2004). 
por caso, atendiendo a su naturaleza, a las consecuencias de la decisión a adoptar y al concreto contexto en que deba producirse" (FJ 9).

En virtud de ello, y si bien en la sentencia de 20 de septiembre había dado la razón a la recurrente, en la de 2 de diciembre da la razón al Gobierno al entender que "no sólo que resolver sobre peticiones de indulto forma parte de la actividad normal del Consejo de Ministros, ya que los expedientes de indulto son numerosos, sino que difícilmente cabe distinguir en ese conjunto de decisiones denegatorias una actividad de orientación politica como la que hemos dicho que nuestro ordenamiento jurídico excluye de la noción de despacho ordinario de los asuntos públicos".

Posteriormente, la sentencia de 28 de mayo de 2013 del Tribunal Supremo, dictada al amparo de un caso muy distinto de los dos anteriores, ya que no era objeto del recurso un Acuerdo del Consejo de Ministros, sino un real decreto, se hizo eco de la argumentación esgrimida en la sentencia de 2 de diciembre de 2005, al considerar que la aprobación del Real Decreto No 1744/2011, de 25 de noviembre, por el que se modifica el Real Decreto No 641/2009, de 17 abril, por el que se regulan los procesos de control de dopaje y los laboratorios de análisis autorizados, y por el que se establecen medidas complementarias de prevención del dopaje y de protección de la salud en el deporte, se "enmarca o cae dentro del ámbito del concepto jurídico indeterminado definido con la expresión 'despacho ordinario de los asuntos públicos', sin necesidad por tanto de que al decidirla concurriera una situación de 'urgencia' o una razón de 'interés general', pues no alcanzamos a percibir, ni tampoco lo expone la actora, qué 'nuevas orientaciones politicas' son las que estableció aquél, o qué 'condicionamiento, compromiso o impedimento' para las que hubiera de fijar el nuevo Gobierno significó su aprobación".

En relación con este Real Decreto, su aprobación vino motivada, según su Exposición de Motivos, porque el Real Decreto No 1462/2009, de 18 de septiembre, por el que se modificó el Real Decreto No 641/2009, de 17 de abril, había "sido anulado por el Tribunal Supremo en fecha 13 de octubre de 2011 por la concurrencia de dos motivos formales de nulidad de pleno derecho. No obstante, es imprescindible que España siga cumpliendo con los compromisos adquiridos en la Convención internacional contra el Dopaje de la Unesco, la cual establece la obligación de nuestro pais de cumplir los principios básicos del Código Mundial Antidopaje".

Por lo que respecta a su contenido, éste se limitó a modificar los artículos 47, 48.2, la definición del término "Control en competición" y a suprimir la definición del término "horas de descanso nocturno" del Real Decreto No 641/2009, de 17 de abril, por el que se regulan los procesos de control de dopaje y los laboratorios 
de análisis autorizados, y por el que se establecen medidas complementarias de prevención del dopaje y de protección de la salud en el deporte.

En ese sentido, el recurso fue desestimado, ya que el real decreto aprobado, pese a ser de enorme enjundia, era políticamente neutro al partir de una urgente necesidad de modificación. Por ello, su aprobación no sólo no supuso un condicionamiento de la orientación política del nuevo Gobierno entrante, sino que era necesario por imprescindible.

Por último, recientemente, en noviembre de 2017, el Tribunal Supremo, en su cuarta y última sentencia sobre este asunto, la STS 4202/2017, de 22 de noviembre, ha consolidado la jurisprudencia precedente, al afirmar que, el "despacho ordinario de asuntos públicos" debe ser interpretado "de conformidad con los criterios jurisprudenciales de nuestras sentencias de Pleno de 2 de diciembre de 2005 y de 28 de mayo de 2013" (FJ 2), no estableciendo, por lo tanto, criterios interpretativos ex novo.

La sentencia-que resolvía el recurso contencioso-administrativo interpuesto por la Junta de Andalucía contra el Real Decreto No 244/2016, de 3 de junio, por el que se desarrolla la Ley No 32/2014, de 22 de diciembre, de Metrología, al argüir que el Real Decreto aprobado por el Gobierno producía una innovación en el ordenamiento jurídico incompatible con la situación de un Gobierno en funciones dado que no es fruto de la urgencia o el interés general- es desestimatoria del recurso.

Para el Tribunal, dicho real decreto, al presentar el doble carácter "de reglamento ejecutivo y norma de transposición del Derecho de la Unión Europea", no es un acto de dirección política por dos motivos. El primero, porque "se trata de una norma secundaria o subalterna, que responde al objetivo de completar y desarrollar la Ley No 32/2014, de Metrología (...) estableciendo reglas técnicas en dichos apartados con sujeción a los principios, directrices o criterios que marca la Ley a desarrollar"; $\mathrm{y}$, en segundo lugar, porque la transposición no puede "catalogarse como un acto de nueva orientación politica, sino que forma parte del proceso complejo de aproximación legislativa de los Estados miembros de la Unión Europea, que constituye además una exigencia para estos" (FJ 3).

En definitiva, de la doctrina jurisprudencial expuesta se extrae como conclusión que, por despacho ordinario de los asuntos públicos que puede acometer el Gobierno en funciones, se comprenden todos aquellos cuya resolución no implique el establecimiento de nuevas orientaciones políticas ni signifique condicionamiento, compromiso o impedimento para las que deba fijar el nuevo Gobierno. Se trata, por lo tanto, de un concepto jurídico indeterminado que ha 
de apreciarse, caso por caso, atendiendo a su naturaleza, a las consecuencias de la decisión a adoptar y al concreto contexto en que deba producirse.

\section{El CONTROL PARLAMENTARIO DEL GOBIERNO EN FUNCIONES}

\subsection{Naturaleza e instrumentos de control parlamentario}

La Constitución española, en su artículo 66.216, estableció las funciones de las Cortes Generales en una triple vertiente: la tradicional legislativa, propia del Parlamento como Poder en el que se residencia la soberanía nacional en los Estados democráticos en los que rige la rule of law, la de aprobación de los Presupuestos ${ }^{17} \mathrm{y}$, por último, la función de control al gobierno ${ }^{18}$.

16 Artículo 66 CE:

"1. Las Cortes Generales representan al pueblo españoly están formadas por el Congreso de los Diputados y el Senado. 2. Las Cortes Generales ejercen la potestad legislativa del Estado, aprueban sus Presupuestos, controlan la acción del Gobierno y tienen las demás competencias que les atribuya la Constitución.

3. Las Cortes Generales son inviolables".

17 Esta cuestión ha sido objeto de una enconada polémica, toda vez que, de su tenor literal, parecía deducirse que los Presupuestos Generales del Estado no eran, en puridad, una ley. Sin embargo, para algunos autores, como Ruiz y García Martínez, los Presupuestos forman parte de la función legislativa de las Cortes. Así, para Ruiz, "los Reglamentos de las Cámaras confirman que la aprobación de los presupuestos se realiza en el marco de la potestad legislativa. Tanto el Reglamento del Congreso como el del Senado regulan las especialidades de este procedimiento dentro del titulo relativo al procedimiento legislativo; en ambos Reglamentos se incorpora además un precepto en el que se dispone que, salvo las especialidades que se contemplan expresamente, en el estudio y aprobación de los Presupuestos Generales del Estado se aplicará el procedimiento legislativo común u ordinario (arts. 133.1 del Reglamento del Congreso y 148.2 del Reglamento del Senado”. RuIz (2001), p. 247. Por su parte, García Martínez sostiene que, "cuando el artículo 134.1 atribuye a las Cortes la capacidad de enmienda del proyecto de Ley de Presupuestos no usa este concepto en su sentido técnico estricto, sino en el genérico de modificación, de manera que lo que la Constitución reconoce es la capacidad de las Cortes para modificar el contenido de los Presupuestos Generales del Estado que presenta el Gobierno. Con ello nuestro Texto fundamental opta abiertamente por la valoración del acto de aprobación por parte de las Cortes del proyecto de Ley de Presupuestos como un acto real y efectivamente legislativo, sin que quepa duda de que los términos del citado artículo 134.1 son rotundos y no plantean ninguna especialidad, a la potestad de enmienda de las Cortes por el hecho de que el objeto de la misma son los Presupuestos del Estado”. García (2002), p. 153. Por último, otros autores como Giménez Sánchez sostienen que con la Ley de Presupuestos las Cortes realizan todas las funciones que tienen encomendadas. Así, "mediante la aprobación de la Ley de Presupuestos Generales, el Parlamento ejerce simultáneamente diversas funciones, entre las que, al menos, pueden distinguirse claramente la potestad legislativa, la financiera (o, lo que es lo mismo, la fijación del régimen de ingresos y gastos del sector público) y la de control de la acción y la política del Gobierno". GiMÉNEZ (2001), p. 171.

18 Esta función, quizá la más relevante desde la perspectiva de la división de poderes en los regímenes parlamentarios, presenta una óptica distinta en la dialéctica mayoría-minoría, como expresa Tudela, ya 
Una función, esta última, la de control al Gobierno, que se configura en los Estados democráticos como consustancial al Estado Constitucional ${ }^{19}$ y que, por ende, resulta imprescindible que se articule de forma eficaz para asegurar la división de poderes desde la limitación del Poder Ejecutivo.

En ese sentido, la función de control parlamentario, siguiendo a Santaolalla, puede ser definida en una primera aproximación como una actividad en la que "un sujeto (el controlante) ejerce sobre otro (controlado) para la tutela de ciertos valores que el primero tiene el deber de proteger, actividad que puede consistir en la verificación de si se han respetado los valores o principios protegidos y en la adopción de medidas sancionatorias o correctivas en caso contrario" 20 .

Con este planteamiento, el control parlamentario es, en suma, "aquella función indeclinable del parlamentarismo democrático que, al utilizar un criterio de oportunidad politica, produce una valoración subjetiva condicionante de la acción del Gobierno, al fijarle líneas de actuación que operarán como marco habilitante, pudiendo verificar en un momento posterior su grado de ejecución en orden a formar un juicio critico para la eventual exigencia de responsabilidad politica" 21 .

Esta definición permite extraer dos notas esenciales, como son la noción de control como función de naturaleza esencialmente política y, en segundo lugar, como función directamente relacionada con el parlamentarismo democrático, de tal suerte que, en definitiva, sin ejercicio activo de control no nos encontramos, en puridad, en un Estado de Derecho.

Ambas definiciones, sin embargo, aun conteniendo la naturaleza esencial del control parlamentario como control político, soslayan su naturaleza jurídica, menor aunque relevante.

Por ello, combinando ambas, en una definición quizá menos sintética pero sí omnicomprensiva del concepto, siguiendo a García Morillo podemos definir el control parlamentario como "la actividad parlamentaria encaminada, a través de una multiplicidad de mecanismos, a la comprobación de la actividad del poder ejecutivo y la verificación de su adecuación a los parámetros establecidos por el Parlamento, susceptible de producir consecuencias diversas, y entre ellas la exigencia de la

que "la acción parlamentaria de la minoría en relación con el Gobierno es control y la que ejerce la mayoría es orientación política". TUdela (2007), p. 83.

19 Rubio (2012), p. 689.

20 Santaolalla (2013), p. 271.

21 Alonso y Alonso (2002), p. 198. 
responsabilidad politica del gobierno, y eventualmente generadora de una influencia variable sobre el comportamiento del sujeto controlado"22.

Entendiendo así el control parlamentario, en su doble vertiente de fiscalización y orientación de la política gubernamental ${ }^{23}$, se comprende bien su relevancia jurídico-política, y el motivo de su especial tratamiento, cuya importancia fue consagrada por el Tribunal Constitucional quien, en el artículo 42 de la Ley Orgánica No 2/1979, de 3 de octubre, del Tribunal Constitucional24, estableció la posibilidad de amparo para los actos sin valor o fuerza de ley, entre los que se encuentran los instrumentos de control parlamentario.

De esta función se deriva, -aunque no se encuentre dentro de la misma función de control, dado que poseen objeto y sujeto totalmente diferentes ${ }^{25}$, la exigencia de responsabilidad política ${ }^{26}$, sin la cual el ejercicio último de la función de control parlamentario quedaría sin razón de ser, una mera declaración política sin consecuencias, quebrando así la naturaleza fiduciaria entre Gobierno y Parlamento que constituye el eje sobre el que pivota la legitimidad política en democracia.

Por lo tanto, el control parlamentario y la exigencia de responsabilidad política trazan un mismo vector que conecta la relación de confianza GobiernoParlamento con el principio de separación o división de poderes, favoreciendo así el equilibrio entre los poderes del Estado.

22 García (1985), p. 94.

23 Así lo entiende Fernández Sarasola, para quien el control "debe definirse funcionalmente, puesto que puede servir tanto para fiscalizar como para dirigir u orientar la política del Gobierno”. FERNÁNDEZ (2000), p. 112.

24 Artículo 42 de la LOTC:

"Las decisiones o actos sin valor de Ley, emanados de las Cortes o de cualquiera de sus órganos, o de las Asambleas legislativas de las Comunidades Autónomas, o de sus órganos, que violen los derechos y libertades susceptibles de amparo constitucional, podrán ser recurridos dentro del plazo de tres meses desde que, con arreglo a las normas internas de las Cámaras o Asambleas, sean firmes".

25 Como explica García Morillo, "el objeto del control es la actividad del ejecutivo, en tanto que el objeto de la exigencia de la responsabilidad política es la comprobación de la subsistencia de la relación fiduciaria que liga al Parlamento con el gobierno". GarCía (1985), p. 79.

26 Para Fernández-Fontecha, la responsabilidad política se puede definir "tanto por las materias sobre las que recae -básicamente la función de gobernar-como por los sujetos de su ejercicio. Aqui se distingue entre el órgano que ejerce la responsabilidad y los órganos que están obligados por la misma, siendo un elemento común que se trata de una responsabilidad ajena a las responsabilidades exigibles en Derecho por razón de un acto ilícito, ya que lo que se sustancia en la citada responsabilidad no es una reparación del daño, sino una medida de pérdida del cargo que en gran parte es actuable a través de procedimientos propios, como la censura, la denegación de la confianza, la reprobación o el impeachment, a reserva naturalmente de la renuncia voluntaria y el cese". FERnÁNDEZ-FonTECHa (2012), pp. 125-126. 
Por ello, el control parlamentario, en palabras de Aragón, es "un elemento inseparable de la Constitución, del concepto mismo de Constitución. Cuando no hay control, no ocurre sólo que la Constitución vea debilitadas o anuladas sus garantías, o que se haga difícil o imposible su "realización"; ocurre, simplemente, que no hay Constitución"27.

En ese sentido, resulta comprensible entender la existencia de los diversos mecanismos de control, que sirven de soporte al derecho de información y al ius in officium de los parlamentarios.

Destacan, entre ellos, las interpelaciones, las mociones y las preguntas orales y escritas, -sin olvidar, naturalmente, las comparecencias de miembros del Gobierno y altos cargos que, aunque posean otro cariz, poseen el mismo objetivo-. $\mathrm{Su}$ diversa naturaleza y objetivos las sitúa en distintos escalones, no tanto de relevancia como de eficacia conforme al objetivo pretendido.

Así lo entendió el Constituyente, quien estableció en el artículo $111^{28}$ de la Constitución la importancia de las interpelaciones y preguntas parlamentarias como instrumento principal, -no citó otros-, de control parlamentario al Gobierno. Cuestión que el Reglamento del Congreso desarrolló, consagrando la trascendencia de ambas como instrumento esencial de control parlamentario al Gobierno, si bien con distintos grados de eficacia práctica.

Así, si bien las interpelaciones, -por su duración y actor interpelado, además de por centrarse en un foco de actualidad-, constituyen una herramienta de control parlamentario de indudable eficacia, -fundamentalmente, por su resonancia en los medios de comunicación dada su actualidad y oportunidad política-, sólo puede sostenerse lo mismo en relación con las preguntas orales en Pleno, - de amplia difusión dado que se realizan en el marco de las sesiones de control al Gobierno-, pero no sucede así con las preguntas escritas, ya que las respuestas rara vez trascienden a los medios de comunicación, salvo en caso muy puntuales.

El Tribunal Constitucional, en cualquier caso, consagró la relevancia de ambos instrumentos, en fechas muy distintas, y con fundamentos muy diversos. Así, y por lo que respecta a las interpelaciones, señaló en los años noventa, en su STC

\footnotetext{
27 Aragón (1987), p. 52.

28 Artículo 111 CE:

"1. El Gobierno y cada uno de sus miembros están sometidos a las interpelaciones y preguntas que se le formulen en las Cámaras. Para esta clase de debate los Reglamentos establecerán un tiempo mínimo semanal.

2. Toda interpelación podrá dar lugar a una moción en la que la Cámara manifieste su posición".
} 
225/1992, de 14 de diciembre, que "pasa a formar parte del contenido del ius in officium (...) como instrumento de información propia para el control del Ejecutivo, que forma parte de la función peculiar de su investidura parlamentaria". Planteamiento que conecta el ius in officium con la relación de confianza establecida con el Ejecutivo a través de la investidura.

Por otro lado, y en relación con las preguntas parlamentarias, desde la STC 220/1991, de 25 de noviembre, el Tribunal Constitucional ha constatado su significación como instrumento de información, poniendo de manifiesto, en su STC 107/2001, de 23 de abril, que "no cabe duda de que la facultad de formular preguntas (....) pertenece al núcleo de su función representativa parlamentaria, pues la participación en el ejercicio de la función de controlar la acción del Consejo de Gobierno y de su Presidente y el desempeño de los derechos y facultades que la acompañan constituye una manifestación constitucionalmente relevante del ius in officium del representante".

De su diversa naturaleza jurídica y concepción constitucional, se puede extraer una definición que permita situar su objeto y sentido, de tal suerte que, siguiendo a algún autor, podemos definirlas como "un acto mediante el cual, un parlamentario pide una breve aclaración, una información o explicaciones sobre un punto o asunto concreto a un miembro del gobierno", constituyendo, en definitiva, "un medio para presionar la acción del ejecutivo en un campo muy concreto, y que, a juicio del diputado, permanecía alejado de la atención gubernamental'29. Estas breves aclaraciones o informaciones, sin embargo, deben tener una indudable trascendencia social ${ }^{30}$, sean las preguntas orales o escritas. En cualquier caso, más allá de su trascendencia, sí conviene resaltar la lógica conexión con el ius in officium ${ }^{31}$.

29 Marco (1998), p. 283.

30 Así lo entiende Santaolalla, quizá refiriéndose a las preguntas orales pero, en cualquier caso, podría ser referido también a las preguntas escritas. Para Santaolalla, "esta concreción del tema objeto de la pregunta no ha de significar sinónimo de particularidad. El parlamentario al formular una de estas interrogaciones está realizando una función pública y, por consiguiente, público ha de ser el interés que inspire su acción. Las preguntas, aun incidiendo sobre puntos precisos, han de referirse a materias que, directa o indirectamente, al menos, tengan una trascendencia social'. SANTAOLALla (1978), p. 56.

31 Así lo expresa García Roca, para quien "las estadísticas corroboran la conexión lógica de sentido entre el manejo de estas herramientas parlamentarias de titularidad individual y la construcción de la relación de representación que los parlamentarios, en cuanto cargos públicos representativos, tienen como función". GARCíA (1999), p. 323. 
En cualquier caso, todas estas figuras, todos estos instrumentos de control parlamentario expresan un concepto de control parlamentario total, es decir, en sentido amplio. Sin embargo, la ausencia de alguna o algunas de ellas no presupone la inexistencia de dicho control al Ejecutivo, toda vez que dicho control existe, aunque sea limitado.

Por otro lado, mención especial merece la proposición no de ley ${ }^{32}$, dado que no se puede considerar, en puridad, como una iniciativa de control parlamentario, toda vez que su función, de orientación política del gobierno, es el impulso ${ }^{33}$ de una determinada política pública, el desarrollo de alguna actividad o un compromiso gubernamental de carácter netamente político ${ }^{34}$. Su naturaleza "peticionaria" a través de un expreso mandato de la Cámara la separa del resto de iniciativas de control y fiscalización de la acción de gobierno para centrarla en el ámbito de las actividades de promoción, impulso o fomento de la acción política gubernamental en una esfera concreta y en un tiempo determinado.

En todo caso, la doctrina del Tribunal Constitucional en relación con el control parlamentario del gobierno ha venido resaltando, al amparo del artículo 23.2 de la Constitución, el derecho de los parlamentarios al uso de las iniciativas de control político, sin más limitación que lo permitido en el reglamento de cada Cámara ${ }^{35}$.

32 Señala Aranda una cuestión muy relevante desde un punto de vista político respecto de estas iniciativas, ya que "En las Proposiciones no de Ley, tan importante como el debate sobre la cuestión que se plantea es la aprobación de la Resolución que conlleva. Con ella, la Cámara expresa su parecer politico y requiere una forma de actuar para el Gobierno". ARANDA (2007), p. 123.

33 Arroyo (2005), p. 142.

34 No obstante, para el Tribunal Constitucional, en su STC 40/2003, de 27 de febrero, son un instrumento híbrido, ya que se utilizan "para poner en marcha la función de impulso político y control del Gobierno pero, también, como una vía adecuada para forzar el debate politico y obligar a que los distintos Grupos de la Cámara y esta misma tengan que tomar expresa posición sobre un asunto o tema determinado" (FJ 7).

35 De su estudio sobre la jurisprudencia constitucional en relación con el control parlamentario, Gómez Corona concluye que "los parlamentarios tienen reconocido, como parte de su status protegido por el articulo 23.2 CE, el derecho a formular preguntas, interpelaciones, mociones y proposiciones no de ley. Asimismo, forma parte del status del parlamentario la facultad de solicitar la información necesaria para el cumplimiento de sus funciones y la comparecencia de los miembros del gobierno y oros cargos públicos, sin más limitaciones que las previstas en cada ordenamiento parlamentario. Ello supone que una indebida obstaculización en el ejercicio de la función de control a través de estos instrumentos, llevada a cabo al margen de lo establecido en el Reglamento Parlamentario resulta susceptible de control por el Tribunal Constitucional, que se ha convertido en garante privilegiado de la posición de las minorias parlamentarias en el desempeño de esta potestad". Gómez (2007), p. 392. 


\subsection{El control parlamentario del Gobierno en funciones durante la XI Legislatura}

Tras la celebración de las elecciones generales del 20 de diciembre de 2015 emergió, por primera vez en nuestra historia democrática, un escenario políticoconstitucional inédito por imprevisto e imprevisible.

Un escenario que se vio reflejado con ocasión de la constitución de las Cámaras, el 13 de enero de 2016, y que se caracterizaba por dos factores, ambos inéditos en nuestra historia: una fragmentación política extrema en el Congreso de los Diputados ${ }^{36}$, articulada en torno a dos bloques ideológicos nada diáfanos y, por otro lado, una cómoda mayoría absoluta en el Senado, caso también único de combinación de dos mayorías, absoluta y simple, en las dos Cámaras tras el mismo proceso electoral.

Inmediatamente después de su constitución, y tras recibir al nuevo Presidente del Congreso ${ }^{37}$, el Rey inició el 18 de enero la preceptiva ronda de consultas previa a la proposición del candidato a la investidura, finalizando el día 22 con una propuesta de candidato a la investidura: Mariano Rajoy, Presidente del Gobierno en funciones.

Sin embargo, la propuesta de candidato, lógica por cuanto representaba la constatación del vencedor de las elecciones generales, se encontró con la nega-

\footnotetext{
36 El número de grupos parlamentarios, -ocho-, y su composición evidencia esta fragmentación: Grupo Popular (120 diputados), Grupo Socialista (89 diputados), Grupo Podemos-En Comú Podem-En Marea (65 diputados), Grupo Ciudadanos (40 diputados), Grupo de Esquerra Republicana (9 diputados), Grupo Catalán (8 diputados), Grupo Vasco (6 diputados) y Grupo Mixto (14 diputados, 4 diputados de Compromís, 2 de IU, 2 de EH-Bildu, 2 de UPN, 1 de Foro Asturias, 1 de Coalición Canaria, 1 de Nueva Canarias y el exdiputado popular Pedro Gómez de la Serna).

37 Signo inequívoco de este nuevo escenario político fue la elección como Presidente del Congreso de un candidato que no pertenecía al grupo parlamentario mayoritario en la Cámara. El elegido, Patxi López, exlehendakari (mayo 2009-diciembre 2012), articuló un compleja composición de la Mesa de la Cámara en la que de los nueve puestos, la Presidencia y la Vicepresidencia Segunda fueron para el Grupo Socialista, la Vicepresidencia Primera, la Vicepresidencia Cuarta y la Secretaría Primera para el Grupo Popular, la Vicepresidencia Tercera y la Secretaría Cuarta para el Grupo Podemos-En Comú Podem-En Marea y las Secretarías Segunda y Tercera para el Grupo Parlamentario de Ciudadanos. Por vez primera, la Mesa del Congreso no contaba con representantes de los grupos nacionalistas, CIU o PNV. No obstante, conviene apuntar que la cesión del Grupo Popular en la elección de Patxi López como Presidente del Congreso pretendía facilitar un proceso recíproco de apoyo con ocasión de la investidura del candidato popular Mariano Rajoy como Presidente del Gobierno.
} 
tiva, en forma de "declinación", del candidato propuesto ${ }^{38}$, viéndose obligado el Rey, de nuevo, a iniciar una nueva ronda de consultas el 27 de enero, que finalizó el 2 de febrero con una nueva y distinta propuesta de candidato a la investidura como Presidente del Gobierno: el candidato del Partido Socialista, Pedro Sánchez ${ }^{39}$.

Mientras comenzaba la segunda ronda de consultas, y ante la dilación del proceso de investidura, el Congreso de los Diputados emite el 26 de enero una nota de prensa tras la constitución de los grupos parlamentarios en la que el nuevo Presidente del Congreso expresa que, "aunque haya un Gobierno en funciones, esta Cámara no está en funciones, y va a empezar a trabajar en el plazo más breve" y que, además, y pese a que se solía esperar a la formación del nuevo Gobierno para adecuar las Comisiones Permanentes Legislativas a su estructura ${ }^{40}$, esta vez no se va a esperar a la investidura.

De hecho, poco antes, y en previsión de un escenario de investidura que se podría alargar aún más de lo previsible ${ }^{41}$, la Secretaría General del Congreso

38 El tenor literal del comunicado de la Casa Real expresa que "En el transcurso de la última consulta, celebrada con don Mariano Rajoy Brey, Su Majestad el Rey le ha ofrecido ser candidato a la Presidencia del Gobierno. Don Mariano Rajoy Brey ha agradecido a Su Majestad el Rey dicho ofrecimiento, que ha declinado".

39 El candidato Pedro Sánchez, como es conocido, fracasó en su intento de ser investido Presidente del Gobierno. El debate de investidura, celebrado los días 1 y 2 de marzo, concluyó con sendas votaciones fallidas los días 2 y 4 de marzo, siendo el primer caso de investidura fracasada. Pese a que había logrado el apoyo de Ciudadanos, firmando un acuerdo, no logró concitar el apoyo de la mayoría de la Cámara. En la primera votación obtuvo 130 votos a favor (PSOE y Ciudadanos) y en la segunda, cuarenta y ocho horas después, 131 (PSOE, Ciudadanos y Coalición Canaria).

40 Esa adecuación se produce con la modificación del artículo 46.1 del Reglamento del Congreso de los Diputados.

41 Como expuse en un artículo publicado en 2012 cuando, paradójicamente, se planteaba la posibilidad de acortar los plazos de la investidura, "Analizando los procesos electorales y las sesiones de investidura que han tenido lugar desde el inicio de la democracia, se observa que entre la celebración de las elecciones y la investidura parlamentaria del presidente del Gobierno ha transcurrido, de media, en torno a un mes. En alguna ocasión incluso mucho más. Así:

$\begin{array}{lll} & \text { Elecciones } & \text { Sesión de investidura } \\ \text { I Legislatura } & \text { 1 de marzo de 1979 } & \begin{array}{l}\text { 30 de marzo de } 1979 \\ \text { 18-25 de febrero de } 1981\end{array} \\ \text { I Legislatura } & & \text { 30 de noviembre-1 de diciembre de } 1982 \\ \text { II Legislatura } & 28 \text { de octubre de } 1982 & 22-23 \text { de julio de } 1986 \\ \text { III Legislatura } & 22 \text { de junio de } 1986 & \text { 29 de octubre de } 1989 \\ \text { IV Legislatura } & 4-5 \text { de diciembre de } 1989 & \text { 8-9 de julio de } 1993 \\ \text { V Legislatura } & \text { 6 de junio de } 1993 & \text { 3-4 de mayo de } 1996 \\ \text { VI Legislatura } & \text { 3 de marzo de } 1996 & \end{array}$


emitió un informe, fechado el 19 de enero, seis días después de la constitución de la Cámara, en el que manifiesta, en relación con las funciones de control que puede ejercer la Cámara mientras dure la prorrogatio gubernamental, que "en la medida en que el Gobierno en funciones conserva ciertas competencias, excepcionalmente y de forma singularizada en cada caso, la Mesa podría admitir y ordenar la tramitación de las iniciativas de control e información (preguntas, interpelaciones, comparecencias y solicitudes de informe) que pudieran plantearse, siempre referidas al ejercicio de las funciones que el artículo 21 de la Ley del Gobierno confiere a éste cuando está en funciones" 42.

En ese sentido, comienzan a evidenciarse ya los primeros síntomas de esa situación de desacompasamiento entre el Ejecutivo y el Legislativo que conducirán al conflicto entre órganos constitucionales entre ambos Poderes.

No obstante, en puridad, el conflicto de atribuciones entre el Congreso de los Diputados y el Gobierno durante la XI legislatura se inició el 10 de marzo de 2016, cuando la Secretaría de Estado de Relaciones con las Cortes remite un oficio y un informe al Presidente del Congreso en relación con la solicitud de comparecencia urgente del Ministro de Defensa formulada por el Grupo parlamentario Socialista ${ }^{43}$, en el que se expone que el criterio del Gobierno es que "la

$\begin{array}{ll} & \text { Elecciones } \\ \text { VII Legislatura } & 12 \text { de marzo de } 2000 \\ \text { VIII Legislatura } & 14 \text { de marzo de } 2004 \\ \text { IX Legislatura } & 9 \text { de marzo de } 2008 \\ \text { X Legislatura } & 20 \text { de noviembre de } 2011\end{array}$

Elecciones

VII Legislatura 12 de marzo de 2000

IX Legill Legislatura 14 de marzo de 2004

$X$ Legislatura 20 de noviembre de 2011

\author{
Sesión de investidura \\ 25-26 de abril de 2000 \\ 15-16 de abril de 2004 \\ 9-11 de abril de 2008 \\ 19-20 de diciembre de 2011"
}

Delgado (2012), p. 204.

Conviene apuntar, además, que en el año 2008, por primera vez en nuestra historia, fue necesaria una segunda sesión de investidura, toda vez que el candidato José Luis Rodríguez Zapatero no obtuvo en primera vuelta ( 9 de abril) la mayoría absoluta necesaria para resultar investido. En la segunda sesión de investidura, celebrada el 11 de abril, sí alcanzó la mayoría simple. Cierto es que, en 1981, el entonces Presidente Leopoldo Calvo-Sotelo requirió de una segunda investidura, pero dicha investidura no fue fruto de un proceso electoral.

42 En el informe se hace una mención especial a las proposiciones no de ley, que en el propio informe se dividen en declarativas, -las que constituyen una manifestación de voluntad-, y propositivas, -las dirigidas al Gobierno con un petitum concreto y determinado-. Las primeras, para la Secretaría General, no presentan problema alguno, mientras que las segundas, "deberian entenderse referidas al Gobierno que se constituya".

43 La solicitud de comparecencia urgente tenía por objeto que el Ministro de Defensa informase acerca de "los asuntos tratados y los acuerdos adoptados en la reunión de ministros de defensa de la OTAN celebrada los días 10 y 11 de febrero de 2016 en Bruselas y, en particular, sobre la nueva operación naval en el Egeo contra las mafias que trafican con refugiados", siendo incluida en el Orden del Día de la Comisión de Defensa 
Cámara no puede someter al Gobierno en funciones a iniciativas de control-entre las que se encuentra la comparecencia incluida en el orden del día de la Comisión de Defensa-, en la medida en la que no existe relación de confianza entre un Gobierno en funciones y el Congreso de los Diputados".

Para el Gobierno, el análisis del Título V de la Constitución, referido a las relaciones entre el Gobierno y las Cortes, no deja lugar a dudas en el sentido de que el control parlamentario va indefectiblemente unido a la relación de confianza otorgada por el Congreso y que, por lo tanto, no puede haber responsabilidad política si no existe tal relación, como prueba, para el Gobierno, el hecho de que "no puede presentar una cuestión de confianza; no puede ser objeto de moción de censura; no puede disolver las Cortes Generales; y no puede presentar iniciativas legislativas". Una relación que ha cesado tras la constitución de la nuevas Cámaras surgidas tras las elecciones generales.

Sin investidura, no puede haber control parlamentario y, en caso contrario, para el Gobierno, podría ser constitutivo de "fraude a la Constitución", dado que "los diputados y grupos parlamentarios elegidos en un nuevo Congreso persiguen controlar, a través del Gobierno cesado, a una mayoría -la de la Cámara de la anterior Legislatura- que había obtenido su mandato de unas elecciones anteriores".

En suma, el criterio del Gobierno en funciones es que la exigencia de responsabilidad política parlamentaria sólo puede ser ejercida sobre un Gobierno investido, y que sus limitadas funciones sólo pueden ser controladas por los órganos jurisdiccionales con base en criterios de legalidad, no de oportunidad política.

Poco después, el 14 de marzo, el Presidente del Congreso, mediante carta remitida a la Vicepresidenta del Gobierno y Ministra de la Presidencia exponía, basándose en un informe de la Secretaría General de la Cámara ${ }^{44}$, un criterio totalmente divergente del manifestado por el Gobierno, al considerar que, a tenor

prevista para la semana siguiente, el 17 de marzo. El Ministro de Defensa, Pedro Morenés, siguiendo el criterio del Gobierno, no compareció, constituyendo el primer caso en el que un miembro del Ejecutivo rechazaba deliberadamente comparecer en el Congreso.

44 En su carta, el Presidente del Congreso exponía también que este informe fue conocido por la Mesa del Congreso en su reunión de 26 de enero, -es decir, poco después de la constitución de la Cámara, el 13 de enero-, y que de acuerdo con él, "la Mesa admitió a trámite la solicitud de comparecencia que ahora se cuestiona". 
del artículo 66 de la Constitución y del artículo 26.2 de la Ley No 50/199745, de 27 de noviembre, del Gobierno, la función de control "existe aun estando el Gobierno en funciones respecto de aquellas cuestiones que son de su competencia", por lo que la decisión del Ejecutivo "conculca su obligación de someterse al control político del Congreso".

La Vicepresidenta, en carta fechada dos días después, el 16 de marzo, se ratifica en el criterio del Gobierno, alegando que la naturaleza de Gobierno en funciones conlleva que sus facultades se encuentran limitadas "al despacho ordinario de los asuntos públicos, es decir, al desarrollo de actividades de carácter puramente administrativo que no impliquen orientación politica alguna", por lo que el Gobierno, carente de la función de indirizzo político, no puede ser objeto del control político del Congreso.

En su carta, por ello, la Vicepresidenta manifiesta que para el Gobierno el conflicto planteado no es de voluntariedad sino de legalidad ${ }^{46}$ y que, por otro lado, en el control que pretende ejercer el Congreso sobre el Ejecutivo, "lo que se plantea es un control más intenso, incluso, que el que le correspondería a un Gobierno que dispusiera de la confianza de la Cámara" 47 . En definitiva, para el Ejecutivo, y tomando como referente nuestra historia democrática, "desde la entrada en vigor de nuestra Constitución, ningún Gobierno de España en funciones se ha sometido al control de una Cámara que no le hubiere otorgado su confianza. Y lo mismo se ha aplicado en asambleas legislativas autonómicas".

Por todo ello, la experiencia del control parlamentario durante la XI Legislatura (13 de enero-3 de mayo de 2016) revela, como se muestra en el cuadro adjunto, que las Cámaras, particularmente el Congreso de los Diputados, han tratado de ejercer su función de control al Gobierno, a través de las múltiples y variadas figuras que el Reglamento de la Cámara permite.

45 Artículo 26.2 de la Ley No 50/1997, de 27 de noviembre, del Gobierno:

"Todos los actos y omisiones del Gobierno están sometidos al control político de las Cortes Generales".

46 "En este punto, le transmito que no estamos, por tanto, ante una cuestión de voluntad del Gobierno sino de estricto cumplimiento de nuestro ordenamiento jurídico $y$, sobre todo, de respeto al régimen de democracia parlamentaria que los españoles nos otorgamos en la Constitución de 1978".

47 La Vicepresidenta realiza esta afirmación tras exponer que "en las últimas semanas, la Mesa que usted preside ha calificado iniciativas de control referidas a asuntos anteriores al cese del Gobierno tras las elecciones generales del 20 de diciembre, que ahora apremian a incorporar en los órdenes del día de las comisiones a partir del momento en que el intento de investidura resultó fallido". Es decir, que la Mesa de la Cámara estaba haciendo un uso indebido por excesivo de las facultades de control al Gobierno. 
Destacan, en ese sentido, y como viene siendo habitual, las preguntas escritas, -con 2581 preguntas escritas registradas-, seguidas de las Proposiciones no de Ley en Comisión, -con 714 Proposiciones-, las preguntas orales en Comisión, -cerca de 190-, y, por último, las Proposiciones no de Ley en Pleno, -con 232 Proposiciones registradas-.

Sin embargo, y pese a ese volumen, lo cierto es que no se han respondido las preguntas escritas formuladas al Gobierno, aunque sí se han debatido un número no desdeñable de Proposiciones no de Ley en Comisión, -201, un 28,15\% de las registradas-, siendo mucho menor el número de Proposiciones no de Ley en Pleno debatidas, -12 , un $5,17 \%$ del total-.

La conclusión, por lo tanto, resulta clara: el control parlamentario, en la XI Legislatura, ha existido, aunque ha sido muy residual, de alcance muy limitado y con escasa efectividad.

\begin{tabular}{|c|c|c|c|c|}
\hline Congreso & Iniciativas & Presentadas & Debatidas & $\begin{array}{c}\text { Trasladas al } \\
\text { gobierno }\end{array}$ \\
\hline \multirow[t]{5}{*}{ Pleno } & Proposiciones no de ley & 232 & 12 & \\
\hline & Interpelaciones & 0 & 0 & \\
\hline & $\begin{array}{l}\text { Nociones consecuencia de } \\
\text { interpelación urgente }\end{array}$ & 0 & 0 & \\
\hline & Comparecencias gobierno & 17 & 1 & \\
\hline & Preguntas orales & 22 & 0 & \\
\hline \multirow[t]{4}{*}{ Comisiones } & Proposiciones no de ley & 714 & 201 & \\
\hline & Comparecencias & 107 & 3 & \\
\hline & Preguntas orales & 187 & 0 & \\
\hline & $\begin{array}{l}\text { Preguntas y solicitudes infor- } \\
\text { mes control escrito }\end{array}$ & 2.581 & 2.245 & \\
\hline
\end{tabular}

Fuente: Ministerio de la Presidencia/Cortes Generales.

\subsection{El conflicto entre órganos constitucionales entre el Congreso y el Gobierno}

El cruce de cartas entre el Gobierno y el Congreso de los Diputados puso de manifiesto la fuerte divergencia de opiniones entre el Ejecutivo y el Legislativo en torno a la facultad de control parlamentario. Una divergencia que, poco después, continuaría con la propuesta de planteamiento de un conflicto entre 
órganos constitucionales del Estado, fechado el 23 de marzo y firmado por la práctica totalidad de los grupos parlamentarios.

Para los grupos firmantes, el control parlamentario "debe entenderse aún mayor cuando se trata de un Gobierno en funciones, ya que el mismo no cuenta con la confianza originaria del Parlamento en su composición política actual, cuya legitimación democrática es directa y además le ha sido concedida más recientemente, por lo que ha de entenderse más cercana a la voluntad popular". Es decir, que la ruptura de la relación fiduciaria Gobierno-Parlamento no sólo no es óbice para ejercer el control político, sino que dicho control debe ser aún mayor, además, dado que "la obligación del gobierno de responder a las iniciativas de control parlamentario no tiene como fundamento esa relación de confianza", porque el Ejecutivo, al someterse al control político, "no está respondiendo de su gestión política ante la Cámara que le otorgó su confianza; sobre todo está respondiendo ante una de las Cámaras que representan al pueblo español, al titular de la soberanía, del que emanan todos los poderes del Estado".

Para los proponentes del conflicto, en suma, "Las Cámaras surgidas de la voluntad popular no pueden estar 'en funciones' hasta que se genere el nuevo Gobierno. Es el Gobierno cesante y en funciones quien está limitado".

Finalmente, el Congreso de los Diputados presentó el 2 de junio un conflicto entre órganos constitucionales ${ }^{48}$ ante el Tribunal Constitucional, que fue admitido a trámite el 9 de junio de 2016, y que aún no ha sido resuelto.

Un conflicto comprensible, toda vez que las costuras de las tradicionalmente cooperativas relaciones entre el Ejecutivo y el Legislativo han entrado en una

\footnotetext{
48 De la trascendencia de la presentación del conflicto entre órganos constitucionales ante el Tribunal Constitucional da buena fe el hecho de que sólo se habían presentado, con anterioridad a éste, dos conflictos en casi cuarenta años, y nunca por el Parlamento. El primero, en 1985 (resuelto en la STC 45/1986, de 17 de abril), fue presentado por el Consejo General del Poder Judicial contra el Congreso y del Senado, mientras que el segundo, del año 2000 (STC 234/2000, de 3 de octubre), resuelve el conflicto entre el Gobierno y el Senado. En suma, y como recuerda Gómez, "ninguna de las dos Cámaras del Parlamento español habia utilizado hasta la fecha la legitimación que ostentan para interponer un conflicto de atribuciones. La activación de este mecanismo procesal-constitucional, en este momento, pone de relieve que los Grupos parlamentarios que lo promueven, e institucionalmente el Congreso de los Diputados, entienden que es el Gobierno el que actúa de forma desleal con la Constitución, al impedir a la Cámara Baja, más por omisión que por acción, que desarrolle con normalidad una de las tres funciones esenciales que tiene constitucionalmente atribuidas, esto es, la facultad de control del Ejecutivo. La idea que sustenta su reclamación es clara: si no hay quien se someta a control, no se puede ejercer la función de control, y si no se puede ejercer esa función, las facultades del poder legislativo quedan ilegitimamente menguadas". GÓmEz (2016), p. 15.
} 
tensión difícilmente resoluble, y en la que, en nuestra opinión, el Congreso de los Diputados posee una razón prácticamente incuestionable.

El Gobierno en funciones, bajo el prisma de su actuación en este período de interinidad, ha pretendido gozar de menores limitaciones de las que gozaba en plenitudo potestatis, limitando no ya su proceder, sino el proceder de quien no sólo no se encontraba limitado, sino obligado a evitar su extralimitación.

Sin perjuicio de ello, dos grupos parlamentarios, el Vasco (PNV) y el Socialista presentaron sendas iniciativas tendentes a modificar la Ley del Gobierno para obligar a someterse al Gobierno en funciones al control político del Parlamento.

El Grupo Vasco, el 18 de marzo de 2016, una vez iniciado el conflicto Gobierno-Parlamento, presentó una proposición de ley "de control politico de las Cortes Generales de los actos y omisiones del Gobierno y del Gobierno en funciones" 49 , que caducó con la disolución de las Cámaras y la convocatoria electoral y que no se ha presentado en la nueva legislatura.

Por su parte, el Grupo Socialista presentó el 8 de agosto, una vez iniciada la XII Legislatura, una proposición no de ley "sobre la reforma de la regulación del Gobierno en funciones contenida en la Ley No 50/1997, de 27 de noviembre, del Gobierno", que no ha sido aún debatida ${ }^{50}$.

49 Esta proposición de ley pretendía modificar dos leyes, la Ley No 50/1997, de 27 de noviembre, del Gobierno, y la Ley No 3/2015, de 30 de marzo, reguladora del ejercicio del alto cargo de la Administración General del Estado, centradas en el sometimiento al control político de las Cortes del Gobierno, con el siguiente tenor:

"Artículo primero. El apartado 2, del artículo 26, de la Ley No 50/1997, de 27 de noviembre, del Gobierno, queda redactado como sigue:

2. Todos los actos y omisiones del Gobierno, incluso del que esté en funciones, están sometidos al control politico de las Cortes Generales.

Artículo segundo. Modificación de la Ley $N^{o} 3 / 2015$, de 30 de marzo, reguladora del ejercicio del alto cargo de la Administración General del Estado.

1. Se añade una nueva letra $f$ ), al apartado 1, del artículo 3, con el siguiente contenido:

f) Sometimiento al control político de las Cortes Generales a que se refiere el apartado 2, del artículo 26, de Ley $N^{o}$ 50/1997, de 27 de noviembre, del Gobierno.

2. Se añade una nueva letra e), al apartado 1, del artículo 25, con el siguiente contenido:

e) El incumplimiento por el alto cargo de la obligación de sometimiento al control político de las Cortes Generales a que se refiere la letraf), del apartado 1, del artículo 3, de la presente Ley".

50 El objetivo de la proposición es:

"1. Delimitar y precisar el alcance de las facultades del Gobierno en funciones referidas al despacho ordinario de asuntos públicos. 
A nuestro juicio, la situación de interinidad gubernamental no excluye, en absoluto, el control político ejercido por la Cámara, que no puede verse "coartado" 51 dado que, como ha manifestado algún autor, "la situación de interinidad, en ningún caso, supone que la división de poderes quede hibernada y por tanto, que el Parlamento existente pueda ser preterido" 52.

Algo que se deduce fácilmente del propio texto constitucional, ya que el propio artículo $66.2 \mathrm{CE}$ "confiere a las Cortes Generales el control de la acción del Gobierno, durante toda su existencia sin distinguir si se encuentra en funciones o no" 53 .

Sin embargo, dicho control, que puede y debe ser pleno como instrumento de protección de la minoría parlamentaria ${ }^{54}$, no puede ser ejercido en sentido amplio sino que, habida cuenta de las propias limitaciones legales establecidas por la Ley del Gobierno, debe amoldarse a las muy acotadas funciones que puede

2. Desarrollar los supuestos en que puede estimarse urgente o de interés general la intervención del Gobierno en funciones distinta al despacho ordinario de asuntos públicos y determinar el procedimiento de acreditación de la urgencia para tales casos".

51 Así lo expresa Gómez Corona, para quien "El Parlamento, como órgano de representación y debate de la ciudadanía no puede verse coartado en su posición constitucional por el hecho de que el nuevo gobierno no haya sido investido". GÓMEz (2016), p. 174.

52 Carrillo (2017), p. 126.

53 No obstante, explica este autor que "En el otro extremo, se encontraría el criterio consistente en la afirmación de que el Gobierno en funciones debe someterse al control con los rasgos típicos de una situación de normalidad. Esto no resulta aceptable, puesto que la naturaleza de un Gobierno en funciones, implica, como se ha visto, la restricción de sus competencias para la resolución de los asuntos ordinarios y urgentes, en aras de la tutela de los intereses generales. En tales circunstancias, resulta razonable considerar que la función parlamentaria de control subsiste, aunque habrá de acompasarse a las circunstancias de existencia de un Gobierno cesante. Las funciones del Parlamento se adecuan, de la misma forma que las del Gobierno, a la situación de interinidad'. De la Peña (1998), p. 349.

54 Sintetiza Fernández Sarasola esta cuestión al exponer que "Cuando el control procede de las minorías, las cautelas para su protección han de ser especiales para lograr la mayor realización posible del principio democrático (que como tal principio es un mandato de optimización). La mayoría se relaciona con el Gobierno de forma bilateral, al estar dotada de facultades decisorias, pero la minoría sólo puede relacionarse con el Ejecutivo introduciendo un tercer término, como es la opinión pública. El movimiento entonces es circular, puesto que el input puede proceder de la sociedad o del Gobierno, y el output tiene como destinatario al Ejecutivo, pero también a la sociedad como apoyo para lograr que la medida sea efectiva. Por esta razón los canales de recepción de información (input) de la minoría (preguntas, interpelaciones, Comisiones de información, comunicaciones de otros órganos estatales...) y de publicidad del control (output, especialmente a través de los medios de comunicación social) deben permanecer impolutos y, en la medida de lo posible, indisponibles por la mayoría puesto que, en realidad, el control parlamentario de la minoría no sólo recae sobre el Gobierno, sino sobre la propia mayoría parlamentaria que lo apoya". FERNÁNDEZ (2000), pp. 112-113. 
ejercer el Ejecutivo ${ }^{55}$. Es decir, el control parlamentario debe ser restringido, no en el sentido de limitado por el propio Gobierno, ni por la propia intensidad del mismo, sino en el sentido de circunscrito a esa función ordinaria y de trámite, máxime cuando la interinidad del Gobierno en funciones se extiende más allá de lo previsible y, consecuentemente, pueden aumentar las circunstancias en la que se podría exceder en su gestión meramente de trámite. Es, por tanto, un Gobierno limitado cuya función última es dar continuidad al sistema ${ }^{56}$.

Esta cuestión, aparentemente sencilla, conlleva no pocas complejidades jurídicas dado que, como hemos señalado antes, bajo el paraguas legal del "despacho ordinario de los asuntos públicos" se esconde un concepto jurídico indeterminado, de marcos confusos y difusos, que exige su análisis caso por caso y, particularmente, en su contexto concreto.

Lo que resulta evidente es que, si como señaló el Tribunal Supremo en su sentencia, España no puede estar sin Poder Ejecutivo "ni unas horas", tampoco puede ni debe estar sin Poder Legislativo. La división de poderes, -especialmente en un sistema parlamentario donde la imbricación Ejecutivo-Legislativo es directa por la legitimidad que recibe el primero del segundo-, exige que aunque exista desacompasamiento funcional entre ambos poderes, no debe existir freno funcional ${ }^{57}$. En definitiva, en un sistema parlamentario, un Ejecutivo limitado puede y debe estar controlado por un Legislativo que, atendiendo a sus restricciones operativas, se centre, también sin excederse, en el marco de actuación que la ley le permite.

En ese sentido, la argumentación esgrimida por el Gobierno en su negativa a someterse a la función de control del Congreso, según la cual, "las competencias de despacho ordinario no tienen interés alguno para el control político, pues se trata de actos que se realizan sin implicar directriz u orientación politica alguna", y que, precisamente por ello "puede afirmarse que estos asuntos carecen de entidad suficiente para ser objeto de control politico parlamentario, incluso en el caso en que fueran realizados por un Gobierno que tiene la confianza de la Cámara", no sólo vulnera la división de poderes al establecer el Gobierno una limitación,

55 En palabras de García Roca, "más que nunca el Gobierno debe estar sometido al control de las Cámaras precisamente porque es un Gobierno en funciones y sus facultades no son ciertas ni indiscutibles". GarCía (2017), p. 147.

56 Visiedo (2017), p. 200.

57 Como recuerda Reviriego, "El que está en funciones es el Gobierno no el Parlamento. No cabe alegar que no hay vínculo fiduciario para no someterse al control'. REVIRIEGO (2017), p. 171. 
-posiblemente inconstitucional-, al ejercicio por parte del Parlamento de una función que tiene encomendada expresamente por la propia Constitución, sino porque pretende determinar el contenido del ejercicio de la propia función de control, lo que conllevaría que el Poder Legislativo se encontrase supeditado al Poder Ejecutivo.

Determinar el "interés" o la "entidad" de los asuntos de despacho ordinario que tramita el Gobierno no es una cuestión que debe definir el Gobierno, sino quien ejerce su control político ${ }^{58}$, el Parlamento, ya que, según el artículo 26.2 de la Ley No 50/1997, del Gobierno, "Todos los actos y omisiones del Gobierno están sometidos al control politico de las Cortes Generales". Y ese "todos" no establece limitación o restricción alguna.

Además, si a renglón seguido en el artículo 26.3 de la propia ley, se señala que "Los actos del Gobierno y de los órganos y autoridades regulados en la presente Ley son impugnables ante la jurisdicción contencioso-administrativa, de conformidad con lo dispuesto en su Ley reguladora", resulta poco comprensible que se pretenda limitar y condicionar la acción del Poder Legislativo mientras se deja incólume la del Poder Judicial, lo que daría lugar a una disfuncional asimetría del equilibrio de poderes ${ }^{59}$ en detrimento del Parlamento ${ }^{60}$, con la curiosa paradoja de

58 En síntesis de Aragón, "en el control politico, aun en los supuestos en que el ordenamiento se refiere a un canon normativo de comprobación, la libertad de valoración de ese canon, las razones de oportunidad que la presiden, la libertad de decisión (política) mediante la cual el control se manifiesta, hacen que el parámetro sea enteramente disponible para el agente del control. Se trata siempre, pues, de una decisión politica basada en razones políticas". ARAGÓN (1986), p. 17.

59 En palabras de Solozábal, crítico con la actuación del Gobierno y el Parlamento, "la prolongación anormal de la crisis de gobierno está originando un deterioro en otras ramas del Estado que no se puede ignorar. Vemos por ejemplo un Parlamento gesticulante e inútil que ofrece un espectáculo no edificante, precisamente. Sin duda la situación ya es complicada de partida, pues es dificil que la relación de equilibrio, consustancial en el sistema parlamentario se mantenga en una situación en la que las Cortes se encuentran en plenitud de facultades, mientras el gobierno cuenta con habilitaciones disminuidas. Ocurre que chocan dos pulsiones igualmente negativas. Un gobierno empeñado en eludir el control parlamentario, partidario de instalarse en una situación de excepcionalidad constitucional en la que el ejecutivo flotase sin admitir seguimiento alguno de sus actuaciones, alegando que no ha de responder al órgano de cuya confianza no depende; y un Congreso empeñado en deshacer la obra legislativa anterior, sabiendo que posiblemente no dispone de plazo temporal para llevar a cabo esa revocación normativa dados los imperativos del procedimiento parlamentario y sobre todo que no existe un gobierno para llevar a efecto la nueva legislación, proponiéndose asi una especie de régimen asambleario convencional, claramente ajeno a nuestro modelo de equilibrio de poderes". Solozábal (2016), p. 2.

60 Para Ripollés, analizando las relaciones Ejecutivo-Legislativo, "el control es una relación sinalagmática entre diferentes órganos, y que el control parlamentario es eje de la obligada relación entre dos órganos del Estado constitucional llamados a entenderse en los términos previstos en la Constitución, sobre un juego de equilibrios entre ambos. Pues bien de la filosofia que subyace en la negativa del Gobierno a someterse a las disposiciones 
que, precisamente cuando el Gobierno es jurídica y operativamente más débil, es sin embargo más fuerte en sus relaciones con el Parlamento, invirtiéndose así la función de control, toda vez que es el propio Ejecutivo quien acaba "controlando" al Legislativo al dirigir y condicionar el ejercicio de la función de control político.

En suma, la ausencia de relación fiduciaria entre el Ejecutivo cesante y la nueva Cámara surgida de las elecciones no puede suprimir la función de control parlamentario ${ }^{61}$, sólo restringirlo a las limitaciones funcionales y competenciales que la ley establece para el Gobierno en funciones, adaptando el control político parlamentario al marco jurídico del Gobierno que, como recuerda algún autor, está limitado pero no "paralizado"62.

\subsection{La experiencia del Derecho comparado}

No resulta difícil comparar la experiencia vivida en esta XI Legislatura con las experiencias de otros países de nuestro entorno, particularmente europeos, donde estas situaciones se han presentado con más frecuencia.

En ese sentido, las dinámicas parlamentarias de algunos países, como el Reino Unido, -donde la conformación del Gobierno es prácticamente inmediata tras unas elecciones-, Italia, -con una larga tradición histórica de gobiernos de interinidad en una misma legislatura, y sucesivos presidentes del Consejo de Ministros de breve mandato, incluso "técnicos" $3_{-}$, Alemania, -la regulación española del Gobierno en funciones tiene su fuente primaria en el modelo ale-

constitucionales en esta materia, que no distinguen entre Gobierno en plenitud y Gobierno en funciones, parece desprenderse una concepción unilateral y no dual del sistema de gobierno parlamentario tal y como determina la Constitución”. Ripollés (2017), p. 180.

61 Aragón aclara que la situación de gobierno cesante o en funciones no conlleva la "suspensión" de la forma de gobierno parlamentaria definida en nuestra Constitución, ya que "en el periodo que transcurre entre la constitución de las Cámaras y la investidura de un nuevo presidente, la forma de gobierno establecida por la CE no puede quedar en suspenso y, por ello, mientras haya Parlamento, viejo o nuevo, y Gobierno (aunque este actúe en funciones), ha de regir la regla básica del régimen parlamentario establecida en el art. 66.2 de la CE: que las Cortes Generales controlan la acción del Gobierno". ARAGÓN (2017), p. 24.

62 García (2017), p. 43.

63 El caso de los gobiernos técnicos en Italia tiene su origen en los años noventa, tras la crisis originada por el caso Tangentópolis y la implosión de la Democracia Cristiana. Desde entonces, ha habido tres gobiernos "técnicos", ninguno de menos de un año de duración: el presidido por Carlo Azeglio Ciampi (28 de abril de 1993-10 de mayo de 1994), el de Lamberto Dini (17 de enero de 1995-17 de mayo de 1996) y el de Mario Monti (16 de noviembre de 2011-28 de abril de 2013). 
mán-, o Portugal, -con una regulación y praxis similar a la de España-, presentan enfoques que pueden servir de referente para la praxis político-constitucional en un escenario inédito para España.

Por ello, de todos los países de nuestro entorno, quizá los casos de Italia o Bélgica representen, por la relativa proximidad de culturas políticas y de regímenes parlamentarios y, sobre todo, de contextos de frecuente interinidad gubernamental, dos ejemplos preclaros en torno a la posibilidad de control parlamentario del Gobierno cesante o en funciones.

En el caso de Italia, país con una larga tradición de inestabilidad gubernamental ${ }^{64}$, la situación de interinidad del Gobierno trae causa primaria de la pérdida de confianza parlamentaria, no tanto de la dilación del proceso de investidura.

Precisamente por ello, y exigiendo la situación de prorrogatio del Gobierno una superior cautela en el ejercicio de sus funciones tras los casos de moción de censura o pérdida de la cuestión de confianza, el control parlamentario de las Cámaras se mantiene intacto aunque la capacidad del Gobierno se encuentre limitada ${ }^{65}$. Se deduce así, fácilmente, que se mantiene también en los casos de prorrogatio tras un período electoral ${ }^{66}$.

Por otro lado, el caso belga resulta paradigmático al objeto de nuestro estudio. No sólo por la frecuencia del Gobierno en funciones en Bélgica ${ }^{67}$, -debido, entre otros factores, a la débil estructura federal y a la ausencia de partidos nacionales, lo que implica que haya, en las regiones de Flandes y Valonia,

64 No en vano, tras la aprobación de la Constitución de 1947, Italia ha tenido 64 gobiernos con 28 primeros ministros, algunos de ellos en períodos distintos. Para un análisis del sistema político italiano y de las causas de su profunda inestabilidad cfr. Mortati (1973), pp. 435-443.

65 De hecho, para Virga, el Gobierno cesado sigue siendo plenamente responsable: "Puesto que el Gabinete saliente sigue siendo responsable frente a las Cámaras y, por lo tanto, está bajo su control, estará obligado a abstenerse de todo acto que implemente ese indirizzo que llevó a disentir a la Cámara y la condujo a un voto de no confianza y, en general, debe abstenerse de tomar un indirizzo politico que exigiese la repetición de la cuestión de confianza". En suma, para este autor, si las funciones gubernamentales no cesan, tampoco la función de control: "Pero precisamente porque las funciones de gobierno no se sustraen al Gabinete cesado, sigue siendo siempre responsable frente a las Cámaras y éstas siempre pueden, a través de los medios de control subsidiario... controlar su función”. VIRGA (1947), p. 50.

66 Así lo entiende Salerno, para quien "La acción de gobierno, también cuando se trata de gobierno cesante en el cargo sólo para la administración ordinaria, queda sin duda sujeta a aquella responsabilidad política llamada difusa que es activable por todas las fuerzas politicas y que, sustanciándose esencialmente en la libertad de crítica desarrollada en el ámbito de la opinión pública, no puede no tener algún reflejo sobre la formación de la voluntad de los electores". Salerno (2008), p. 4.

67 En 1978-1979, 1987, 1991, 2007 y en 2010-2011. Nunca menos de cien días. 
partidos similares en ideología y programa, pero pertenecientes a regiones y comunidades diferentes-, sino porque posee el triste récord de duración de un Gobierno en funciones en Europa y en todo el mundo, con 541 días en total, prácticamente, año y medio ${ }^{68}$.

No obstante, precisamente por su tradicional situación de excepcionalidad política e inestabilidad gubernamental, resulta conveniente mencionar la práctica seguida en torno al control parlamentario del Gobierno cesante en el Parlamento belga.

En ese sentido, procede constatar que el control parlamentario sí se ha producido. Como se puso de manifiesto en 2010-2011, cuando la prorrogatio gubernamental excedió de los quinientos días, la actividad del Parlamento federal belga se desarrolló con normalidad aunque, naturalmente, no con plenitud.

Ejemplo de ello lo constituyen tanto las preguntas escritas formuladas por los diputados como las sesiones de control al gobierno con preguntas orales e interpelaciones, en todos los casos abundantes ${ }^{69}$, revelando una actividad parlamentaria intensa y extensa ${ }^{70}$, que no cesó durante el período de interinidad del Gobierno.

El ejemplo belga, el más revelador, se convierte así en referencia al constatar cómo la dilación de la prorrogatio gubernamental no supuso un freno a la función parlamentaria de control sino, antes al contrario, la permanencia y crecimiento de la misma en sus principales figuras e iniciativas.

68 Es el período comprendido entre las elecciones federales del 13 de junio de 2010 y la toma de posesión de Elio di Rupo como Primer Ministro belga el 6 de diciembre de 2011. La existencia de una Cámara muy atomizada, con doce partidos representados, ninguno mayoritario, exigió el lento y complejo, -habitual en Bélgica-, proceso de formación del gobierno, a través de la nominación por el Rey de las figuras del informateur, el préformateur, el médiateur, el clarificateur, el conciliateur y el formateur. Finalmente, el acuerdo de gobierno entre seis partidos de amplio espectro político permitió poner fin al impasse de interinidad gubernamental. No obstante, previamente, en 2007, Bélgica sufrió un proceso similar, aunque de menor duración, de 194 días. Se produjo también tras unas elecciones federales, en este caso las del 10 de junio de 2007, y se extendió hasta el 20 de marzo de 2008, cuando Yves Leterme asumió la responsabilidad de gobierno.

69 Entre junio de 2010 y diciembre de 2011 se registraron 4.022 preguntas escritas y 589 preguntas orales en Pleno (20 de media por sesión plenaria, de ellas, 262 formuladas por diputados pertenecientes a grupos de la minoría). De hecho, el Parlamento belga recuperó, a partir de los inicios de 2011, sus niveles "normales" de actividad parlamentaria. BAESELEN et al. (2014), pp. 34 y ss.

70 Van Aelst y Louwerse (2014), p. 485. 


\section{Conclusiones}

La situación de prorrogatio gubernamental vivida en España tras las elecciones generales del 20 de diciembre de 2015 hasta el 4 de noviembre de 2016 constituyó el período de mayor duración de un Gobierno cesante o en funciones en nuestra historia democrática, acostumbrado hasta entonces a una interinidad media que nunca había excedido de los treinta días, salvo en 1996, que se alargó a poco más de dos meses.

Una circunstancia inédita que, además de las propias complejidades del proceso de investidura parlamentaria y la repetición, en junio de 2016, de las elecciones generales, puso en cuestión las costuras de nuestro marco constitucional, al producirse, por tercera vez, pero primera protagonizada por el Ejecutivo, un conflicto entre órganos constitucionales: el Gobierno y el Parlamento.

Un conflicto suscitado por la negativa gubernamental a someterse al control parlamentario de las Cámaras, amparándose en que, rota la relación fiduciaria entre el Congreso de los Diputados y el Gobierno tras las elecciones, el Gobierno cesante no se encontraba vinculado por la nueva Cámara surgida de las urnas y que, por lo tanto, en tanto no se produjese la investidura parlamentaria del Presidente del Gobierno, no se iba a someter a dicho control.

A causa de ello, el Gobierno se negó a comparecer en el Congreso y en el Senado, salvo cuando así lo consideró oportuno, así como a responder a las diversas iniciativas parlamentarias a través de las cuales ejerce el Parlamento la función de control, como las preguntas escritas o las preguntas orales en las sesiones plenarias, entre otras.

En ese sentido, conviene recordar que los diversos instrumentos de control parlamentario encuentran su sentido en la fiscalización, -una suerte de responsabilidad in vigilando-, que debe realizar el Parlamento al Gobierno en un régimen democrático.

Estos instrumentos, por lo tanto, sirven a un fin determinado, que no es otro que garantizar el acceso a la información de los parlamentarios para ejercer dicha fiscalización y evitar, con ello, que la ausencia de información genere un desequilibrio en la división de poderes en favor del gobierno que favorezca un uso arbitrario sus funciones y competencias.

La negativa gubernamental, por todo ello, no sólo limitó el ius in officium propio de los parlamentarios que forma parte del artículo 23.2 de la Constitución, sino que impidió el ejercicio de una de las dos funciones clásicas del Parlamento. 
En consecuencia, la experiencia de la brevísima XI Legislatura, -13 de enero-3 de mayo de 2016-, revela que los mecanismos de control parlamentario se han ejercido de forma muy limitada, sin apenas efectividad.

Así, mientras los diversos Grupos parlamentarios constituidos comenzaron la legislatura articulando una serie de iniciativas de control parlamentario, -particularmente, y como ya venían anunciando con carácter previo a la constitución de las Cortes, a través de preguntas escritas y Proposiciones no de Ley-, el Gobierno, primero con ocasión de las solicitudes de comparecencia y, después, con la no respuesta a las iniciativas formuladas, no sólo no se sometió pasivamente al control que ejercían los parlamentarios, sino que ejerció una oposición activa a dicho ejercicio.

El debate, no obstante, pudo ser desviado, en una suerte de posición intermedia, hacia la tipología del control, esto es, qué iniciativas y con qué contenido, dado que, de la misma manera que un Gobierno en funciones no se encuentra capacitado, por ejemplo, para responder acerca de las políticas de función pública o violencia de género que va a implementar por carecer de la función de indirizzo político, sí puede, por el contrario, responder acerca del número de empleados públicos existentes o las víctimas violencia de género en 2016 en alguna provincia, aunque, en cualquier caso, optó por no responder a la inmensa mayoría de las iniciativas de control.

Es definitiva, si el control pretende la clarificación, crítica u orientación de las políticas derivadas de la función de indirizzo político, el control no puede ser ejercido, porque el Gobierno carece del indirizzo político de impulso, de la función de Gobierno necesaria para poner en marcha cualquier acción o iniciativa política.

Por el contrario, si el control parlamentario pretendía la fiscalización de la gestión del Gobierno en funciones, no existe limitación alguna para que el Gobierno pueda ser controlado en su labor de "despacho ordinario de los asuntos públicos".

El Gobierno en funciones, sin embargo, ha asimilado ambos conceptos, sin filtro, con una interpretación extensiva que no ha dejado hueco posible al legítimo ejercicio de la función parlamentaria de control.

Otros países, como por ejemplo Bélgica, con una larga tradición de gobiernos en prorrogatio, sí han acogido la necesidad del control político de los asuntos despachados en interinidad gubernamental, y así lo ha llevado a cabo, como se ha podido comprobar en 2010-2011, cuando el Gobierno se mantuvo cesante durante 541 días. 
En síntesis, la cuestión es clara: si hay Gobierno, aunque sea en prorrogatio, debe haber control parlamentario al mismo, porque no puede haber un Gobierno sin control, sean cuales sean sus competencias.

\section{Bibliografía CiTADA}

Alonso de Antonio, José Antonio y Alonso de Antonio, Ángel Luis (2002). Introducción al Derecho Parlamentario (Madrid, Editorial Dykinson).

ARAGón Reyes, Manuel (1986). "El control parlamentario como control político", en Revista de Derecho Político (Año 8, No 23), pp. 9-40.

Aragón Reyes, Manuel (1987). "El control como elemento inseparable del concepto de Constitución”, en Revista Española de Derecho Constitucional (Año 7, No 19), pp. 15-52.

Aragón Reyes, Manuel (2017). "Legislatura fallida e investidura convulsa. Aná-

lisis y consecuencias", en Revista Española de Derecho Constitucional (Año 37, No 109), pp. 15-34.

Aranda Álvarez, Elviro (2007). “Transformaciones en los instrumentos de control parlamentario", en Teoría y Realidad Constitucional (Año 10, No 19), pp. 105-134.

Arroyo Domínguez, Jesús (2005). "Apuntes sobre la proposición no de ley: concepto y práctica parlamentaria", en Corts: Anuario de derecho parlamentario (Año 11, No 16), pp. 135-152.

Baeselen, Xavier; Toussaint, Sandra; Pilet, Jean-Benoît, y Brack, Nathalie (2014). "Quelle activité parlementaire en période d'affaires courantes?". Les cahiers de l'ULB et du PFWB, (Año 1, No 1), pp. 1-58.

Brage Camazano, Joaquín y Reviriego Picón, Fernando (2006). "Gobierno en funciones y despacho ordinario de los asuntos públicos (las SSTS de 20 de septiembre y 2 de diciembre de 2005)". Teoría y Realidad Constitucional (Año 9, No 18), pp. 445-486.

Carrillo, Marc (2017). "Las atribuciones del gobierno en funciones". Revista Española de Derecho Constitucional (Año 37, No 109), pp. 121-154.

Delgado Ramos, David (2012). "Breves notas sobre una cuestión controvertida: ¿Es posible acortar los plazos para la investidura del candidato a Presidente del Gobierno?". Asamblea: Revista parlamentaria de la Asamblea de Madrid (Año 14, No 26), pp. 203-216. 
De la Peña Rodríguez, Luis (1998). "El control parlamentario del Gobierno en funciones a la luz de la Constitución", en Parlamento y control del gobierno, coordinado por Francesc Pau i Vall (Navarra, Aranzadi), pp. 345-350.

FernÁndeZ-Fontecha Torres, Manuel (2012). Teoría y Jurisprudencia parlamentaria. Un estudio de teoría y jurisprudencia constitucional sobre el Parlamento (Madrid, Cortes Generales).

Fernández Sarasola, Ignacio (2000). "El control parlamentario y su regulación en el ordenamiento español”. Revista Española de Derecho Constitucional (Año 20, No 60), pp. 89-114.

García Fernández, Javier (2017). "Encuesta sobre el Gobierno en funciones". Teoría y Realidad Constitucional (Año 21, No 40), pp. 43-68.

García MartíneZ, Asunción (2002). "Las enmiendas en el procedimiento presupuestario", en I Jornadas de Derecho Parlamentario de la Asamblea de Madrid. Parlamento y Presupuestos, Asamblea de Madrid.

García Morillo, Joaquín (1985). El control parlamentario del Gobierno en el ordenamiento español (Madrid, Congreso de los Diputados).

GarCía Roca, Javier (2017). “¿Puede rechazar el control parlamentario un Gobierno en funciones?", en Lecciones constitucionales de 314 días con el Gobierno en funciones, coordinado por Elviro Aranda (Valencia, Tirant), pp. 133-152.

García Roca, Javier (1999). Cargos públicos representativos. Un estudio del artículo 23.2 de la Constitución (Aranzadi, Navarra).

GiménEZ SÁncheZ, Isabel (2001). "El incumplimiento del Gobierno de la obligación de presentar el proyecto de ley de Presupuestos Generales (La prórroga de los Presupuestos de la Comunidad Autónoma del País Vasco)". Revista Española de Derecho Constitucional (Año 21, No 63), pp. 169-194.

Gómez Corona, Esperanza (2007). "El control parlamentario en la jurisprudencia constitucional". Teoría y Realidad Constitucional (Año 11, No 19), pp. 365-396.

Gómez Corona, Esperanza (2016). "Las limitaciones del Parlamento recién constituido durante la prorrogatio gubernamental”. Revista de Derecho Político (Año 43, No 96), pp. 149-180.

Gómez Fernández, Itziar (2016). "Cuando el Congreso quiere (y no puede) controlar al Gobierno en funciones: singularidades constitucionales y soluciones inéditas". Ars Iuris Salmanticensis (Vol. 4, No 1), pp. 11-20. 
Marco Marco, Joaquín J. (1998). "Las preguntas parlamentarias: las preguntas de interés general al Presidente del Ejecutivo", en Parlamento y control del gobierno, coordinado por Francesc Pau i Vall (Navarra, Aranzadi), pp. 283-290. Mortati, Costantino (1973). Le forme di Governo (CEDAM, Padua).

Reviriego Picón, Fernando (2004). "La regulación del Gobierno en funciones en los ordenamientos autonómicos a propósito del caso cántabro". Anuario Jurídico y Económico Escurialense (Año 33, No 37), pp. 351-386.

Reviriego Picón, Fernando (2004). "Un supuesto de Gobierno en funciones: la ubicuidad de Ruiz-Gallardón, Alcalde-Presidente”. Revista Internauta de Práctica Jurídica (Año 6, No 13), pp. 8-20.

Reviriego Picón, Fernando (2017). "La permanencia en funciones del Gobierno en la doctrina del Tribunal Supremo". Revista Española de Derecho Constitucional (Año 37, No 109), pp. 379-405.

Reviriego Picón, Fernando (2017). "La permanencia en funciones del Gobierno, algunas reflexiones tras 314 días de interinidad", en Lecciones constitucionales de 314 días con el Gobierno en funciones, coordinado por Elviro Aranda (Valencia, Tirant), pp. 153-177.

Ripollés Serrano, María Rosa (2017). "Gobierno en funciones y control parlamentario”. Revista Española de Derecho Constitucional (Año 37, No 109), pp. 155-183.

Rubio Llorente, Francisco (2012). La forma del poder. Estudios sobre la Constitución (Madrid, Centro de Estudios Políticos y Constitucionales), Volumen II.

Ruiz García, José Ramón (2001). "De nuevo sobre la naturaleza de la Ley de Presupuestos (Comentario a la sentencia de la Audiencia Nacional de 7 de noviembre de 2000). Revista Española de Derecho Constitucional (Año 21, No 63), pp. 235-254.

Salerno, Giulio M. (2008). "Sui poteri del governo dimissionario e delle Camere in regime di prorrogatio", (fecha de consulta: 20 de septiembre de 2017). (Disponible en: http://www.federalismi.it/nv14/editoriale.cfm?eid=126\&co

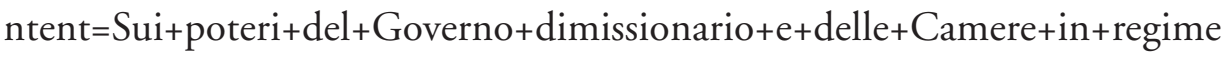
+ di+prorogatio\&content_auth=Giulio+M.+Salerno).

Santaolalla López, Fernando (2013). Derecho Parlamentario Español. (Madrid, Editorial Dykinson).

Santaolalla López, Fernando (1978). "Las preguntas, instrumento parlamentario de control”. Documentación Administrativa (Año 4, No 178), pp. 49-88. 
SolozÁbal EchaVArRía, Juan José (2016). "La nefasta interinidad prolongada del Gobierno”. (Disponible en: https://www.elimparcial.es/noticia/163719/).

Tudela Aranda, José (2007). "La renovación de la función parlamentaria de control”. Teoría y Realidad Constitucional (Año 11, No 19), pp. 75-104.

Van Aelst, Peter y Louwerse, Tom (2014). "Parliament without Government: the Belgian Parliament and the Government Formation Processes of 20072011 ". West European Politics (Año 37, Vol. 37), pp. 475-496.

VIRGA, Pietro (1948). La crisi e le dimissioni del Gabinetto (Giuffrè, Milán).

Visiedo Mazón, Francisco J. (2017). "Un Gobierno en funciones, no un Parlamento en funciones", en Lecciones constitucionales de 314 dias con el Gobierno en funciones, coordinado por Elviro Aranda (Valencia, Tirant), pp. 179-203.

\section{NORMAS JURÍDICAS CITADAS}

\section{CONSTITUCión ESPAÑOLA}

Ley Orgánica No 2/1979, de 3 de octubre, del Tribunal Constitucional. Boletín Oficial del Estado número 239, 5 de octubre de 1979.

Ley No 50/1997, de 27 de noviembre, del Gobierno. Boletín Oficial del Estado número 285, 28 de noviembre de 1997.

\section{JURISPRUDENCIA CITADA}

Sentencia del Tribunal Supremo 5639/2005 (Sala Tercera, Contencioso-Administrativo), de 20 de septiembre de 2005 (contra el Acuerdo del Consejo de Ministros "en funciones" que concedía la extradición de una ciudadana británica).

Sentencia del Tribunal Supremo 8303/2005 (Sala Tercera, Contencioso-Administrativo), de 2 de diciembre de 2005 (contra el Acuerdo del Consejo de Ministros "en funciones" denegatorio de indultos).

Sentencia del Tribunal Supremo 2602/2013 (Sala Tercera, Contencioso-Administrativo), de 28 de mayo de 2013 (sobre la aprobación de un Real Decreto de desarrollo reglamentario por un Gobierno en funciones).

Sentencia del Tribunal Supremo 4202/2017 (Sala Tercera, Contencioso-Administrativo), de 22 de noviembre de 2017 (sobre la aprobación de un Real Decreto de desarrollo reglamentario por un Gobierno en funciones). 
